Supporting Information

\title{
Bioactive polyhydroxanthones from Penicillium purpurogenum
}

Jinghua Xue, ${ }^{\dagger}$ Hanxiang Li, ${ }^{\dagger}$ Ping Wu, Liangxiong Xu, Yunfei Yuan, Xiaoyi Wei ${ }^{*}$

Key Laboratory of Plant Resources Conservation and Sustainable Utilization and Guangdong Provincial Key Laboratory of Digital Botanical Garden, South China Botanical Garden, Chinese Academy of Sciences, Xingke Road 723, Tianhe District, Guangzhou 510650, People's Republic of China

Corresponding Author

" Xiaoyi Wei, Tel.: +86-20-3725-2538; Fax: +86-20-3725-2537,

E-mail address: wxy@scbg.ac.cn (X. Wei). 


\section{Contents}

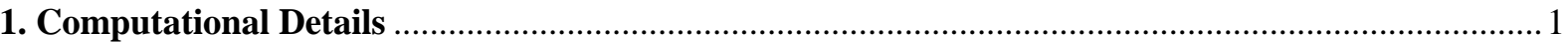

Table S1. Calculated energies and equilibrium populations of conformers of 2-4 .............................. 3

Figure S1. Comparison of measured ECD spectra of $\mathbf{3}$ and $\mathbf{9}$ with calculated ECD of $\mathbf{3} \ldots \ldots \ldots \ldots \ldots \ldots . . . . . . . . . .3$

Figure S2. Reaction coordinate diagrams for C-10a epimerization of 10a and 11a............................ 4

Figure S3. Geometries of the stational points in epimerization of 10a. .............................................. 4

Figure S4. Geometries of the stational points in epimerization of 11a............................................ 4

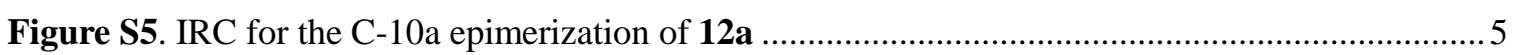

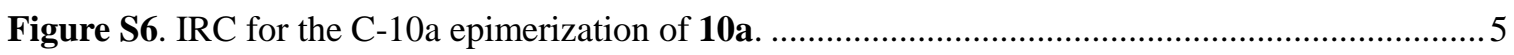

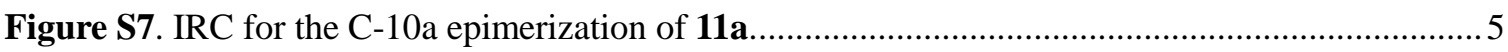

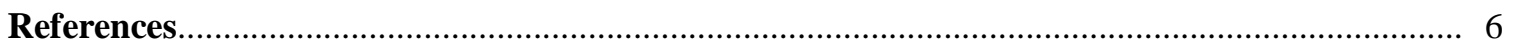

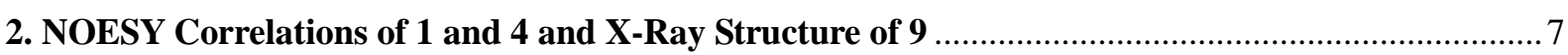

Figure S8. Key NOE correlations in NOESY spectra of $\mathbf{1}$ and $\mathbf{4}$ in DMSO- $d_{6} \ldots \ldots \ldots \ldots \ldots \ldots \ldots$

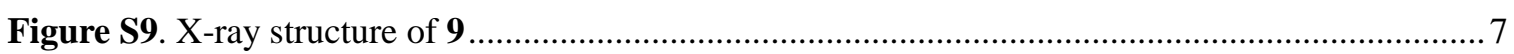

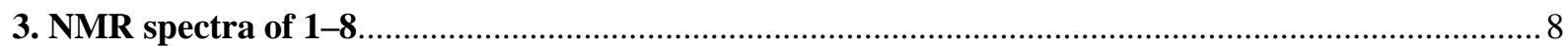

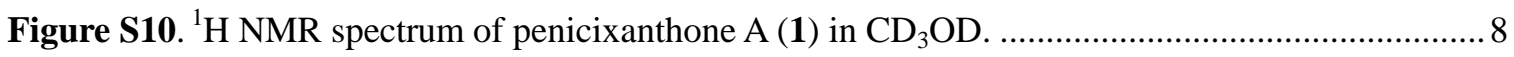

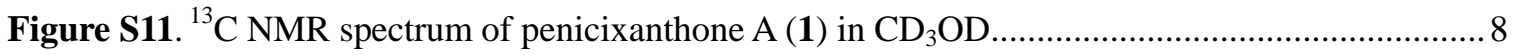

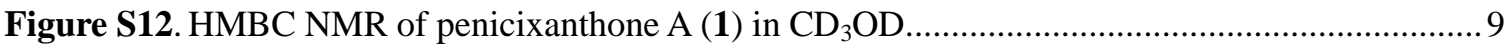

Figure S13. NOESY NMR of penicixanthone $\mathrm{A}(\mathbf{1})$ in $\mathrm{CD}_{3} \mathrm{OD} \ldots \ldots \ldots$

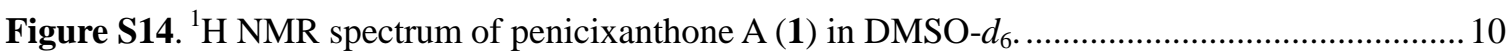

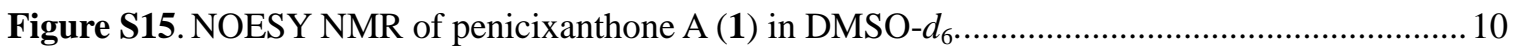

Figure S16. ${ }^{1} \mathrm{H}$ NMR spectrum of penicixanthone $\mathrm{B}(2)$ in $\mathrm{CDCl}_{3}$................................................ 11

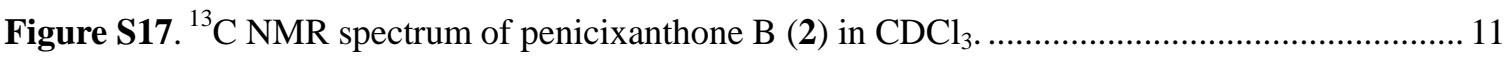

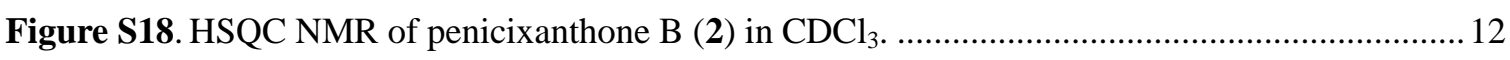

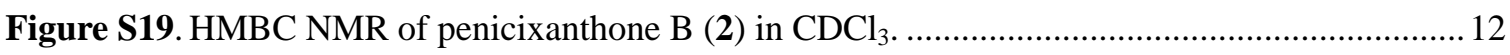

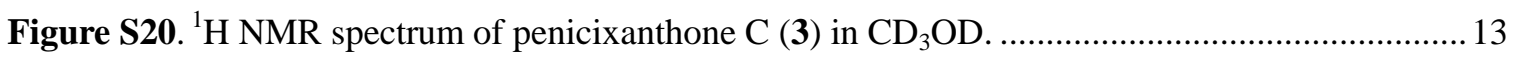

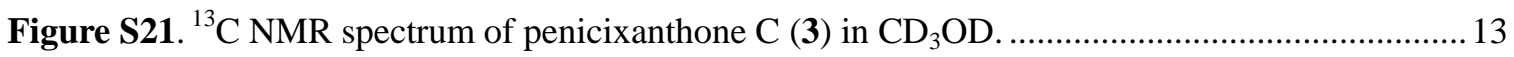

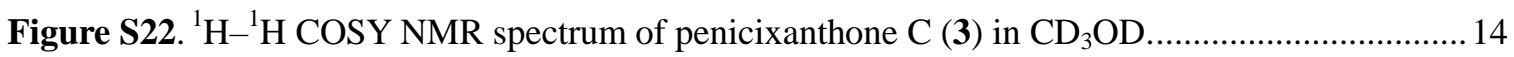

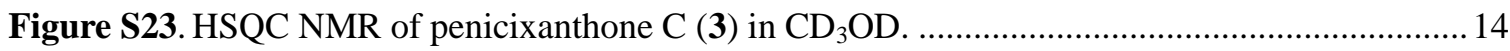

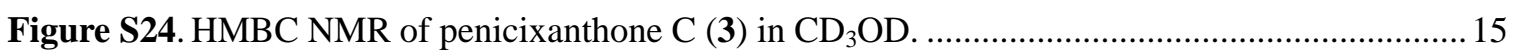

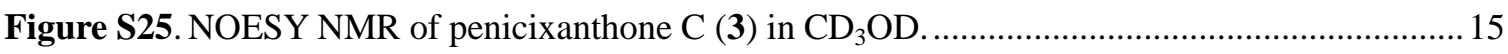

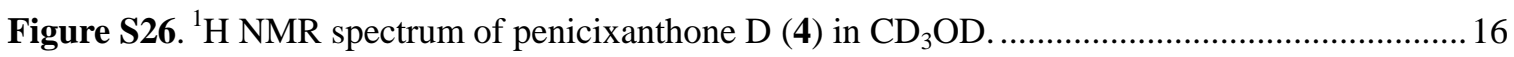

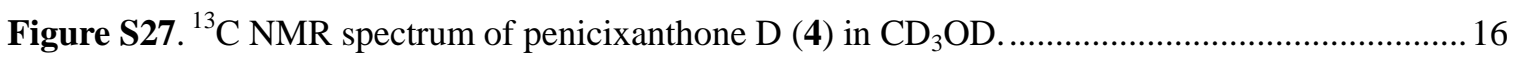

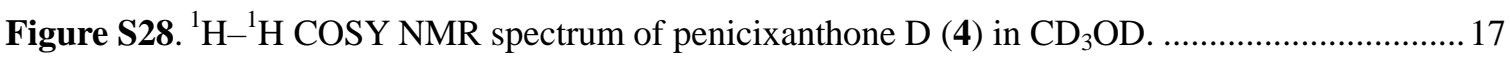

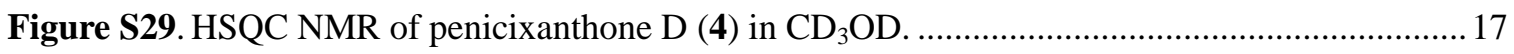

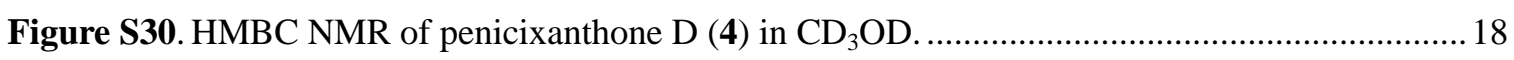

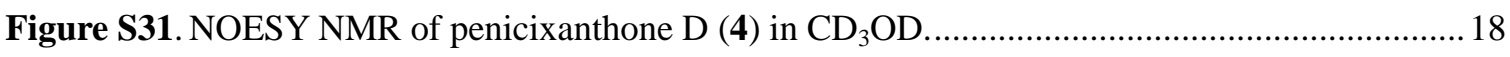

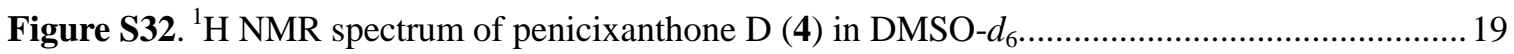

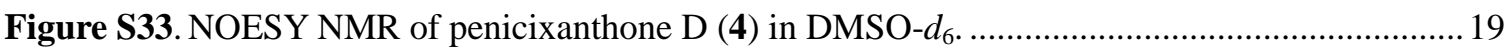

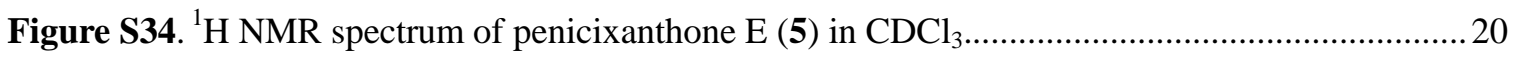

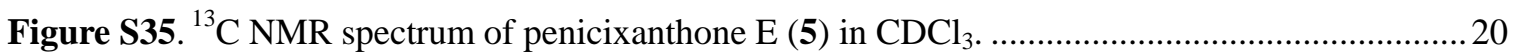

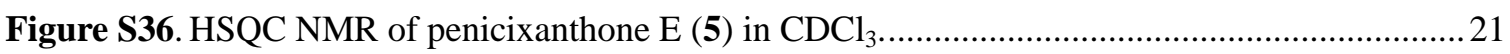

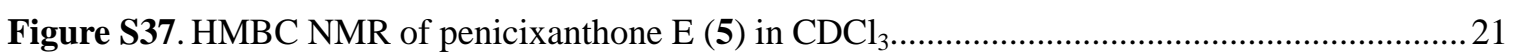




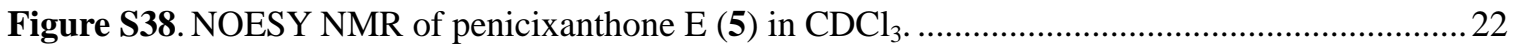

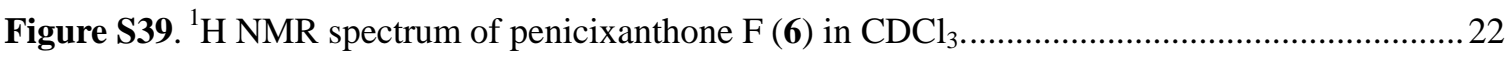

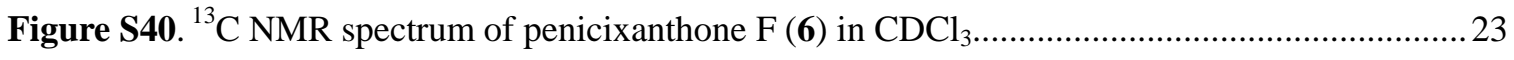

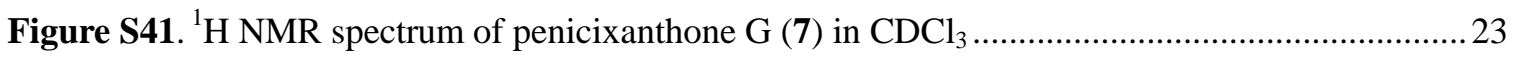

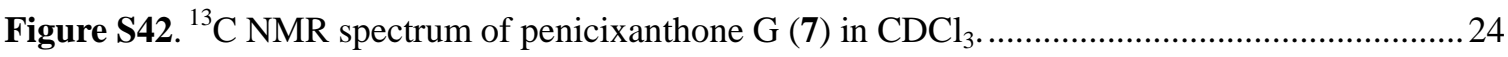

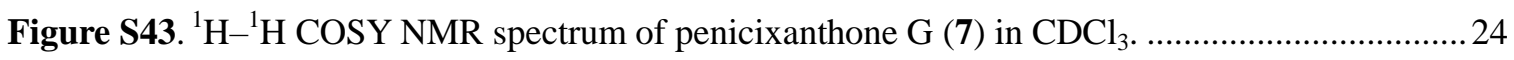

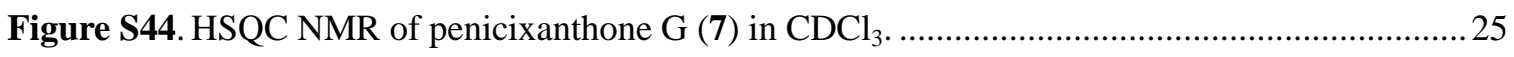

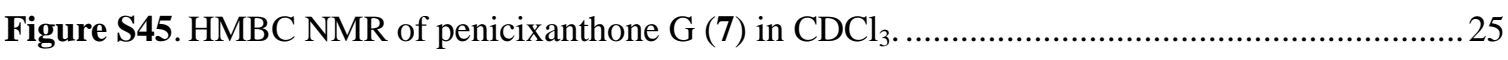

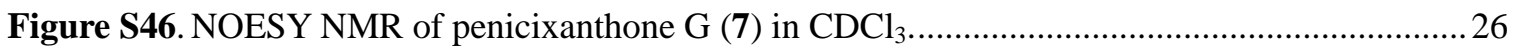

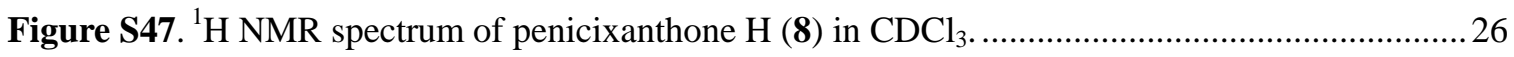

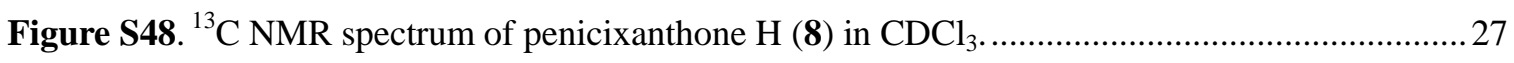

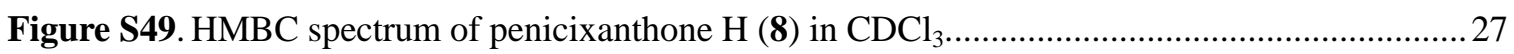




\section{Computational Details}

Molecular Merck force field (MMFF) calculations were done using Spartan'14 program (Wavefunction Inc., Irvine, CA, USA). Density functional theory (DFT) and time-dependent density functional theory (TDDFT) calculations were performed with Gaussian09 RevD.01. ${ }^{1}$ Double hybrid DFT calculations were conducted with ORCA 4.1.0 program package. ${ }^{2}$ In order to save computational cost, the succinyl group in innate structures of compounds $\mathbf{3}$ was truncated to an acetyl group. For calculations of ECD spectra, low-energy conformers within a $10 \mathrm{kcal} / \mathrm{mol}$ energy window from MMFF conformational search were subjected to geometry optimization using DFT method at the B3LYP/6-31G(d,p) level. Frequency calculations were run at the same level to verify that each optimized conformer was a true minimum and to estimate their relative thermal $(\Delta E)$ and free energies $(\Delta G)$ at $298.15 \mathrm{~K}$. Energies of the low-energy conformers were re-calculated at the B3LYP/6-311+G (d,p). Solvent effects were taken into account in all DFT calculations, by using polarizable continuum model (PCM) for $\mathrm{MeOH}$. The TDDFT calculations were performed using the hybrid B3LYP ${ }^{3}$ and M06-2X ${ }^{4}$ functionals, and Ahlrichs' basis set TZVP (triple zeta valence plus polarization) ${ }^{5}$ with the solvation model PCM for MeOH. The ECD spectra were generated by the program SpecDis ${ }^{6}$ using a Gaussian band shape. Equilibrium population of each conformer at $298.15 \mathrm{~K}$ was calculated from its relative free energies using Boltzmann statistics. The calculated spectra of compounds were generated from the low-energy conformers according to the Boltzmann weighting of each conformer in $\mathrm{MeOH}$ solution.

The theoretical simulations of the reaction pathway for C-10a epimerization were carried out with the deprotonated tetrahydroxanthone 12a, dihydroxanthone 10a, and 6,7-epoxytetrahydroxanthone 11a as the reactants. The structures of $10 \mathbf{a}-12 \mathbf{a}$ were built and subjected to MMFF conformational searches followed by DFT geometry optimization. The afforded global energy minima were used as the staring conformers for subsequent calculations. The first transition states (TS1s) for 10a-12a were located by relaxed potential energy surface (PES) scans along the increasing distance of the bond between O-10 and C-10a followed by geometry optimizations using the Berny procedure and authenticated by the intrinsic reaction coordinate (IRC) calculations. The intermediates $\mathbf{1 3 a}-\mathbf{1 5 a}$ and $\mathbf{1 3 b} \mathbf{b}-\mathbf{1 5 b}$ 
were obtained from the last forward IRC products by MMFF conformational searches followed by DFT geometry optimization. The second transition states (TS2s) were located by PES scans of 13b-15b along the decreasing distance between O-10 and C-10a followed by the calculations as described above for TS1s. The final deprotonated products were obtained from the last forward IRC products of TS2s as described above for the intermediates. DFT optimizations of these stationary points were all conducted at the B3LYP-D3BJ ${ }^{7} /$ def2-SVP $/ \mathrm{PCM}\left(\mathrm{H}_{2} \mathrm{O}\right)$ level of theory. Harmonic vibrational frequency calculations were made at the same level of theory in order to characterize these points (minima or transition states) and to estimate their relative thermal $(\Delta E)$ and free energies $(\Delta G)$ at $298.15 \mathrm{~K}$. In order to obtain more accurate electronic energies, single point calculations were carried out using the double hybrid DFT method at the PWPB95-D3BJ ${ }^{9}$ /def2-QZVPP ${ }^{10} / \mathrm{SMD}^{11}\left(\mathrm{H}_{2} \mathrm{O}\right)$ level with RIJK approximations, tightSCF criteria, and grid5 integrity. 
Table S1. The B3LYP/6-311+G(d,p)/PCM(MeOH) calculated total electronic energies $\left(\varepsilon_{0}\right)$, relative thermal energies $(\Delta E)$, relative free energies $(\Delta G)$, and equilibrium populations $(\mathrm{P})$ of low-energy conformers of compounds $\mathbf{1 , 2 , 4}$, and 5 .

\begin{tabular}{lcccc}
\hline conformer & $\varepsilon_{0}($ Hartree $)$ & $\Delta E(\mathrm{kcal} / \mathrm{mol})$ & $\Delta G(\mathrm{kcal} / \mathrm{mol})$ & $\mathrm{P}(\%)^{a}$ \\
\hline compound 2 & & & & \\
2a & -1108.11062258 & 0.0 & 0.0 & 69.8 \\
2b & -1108.11035313 & 0.27 & 0.50 & 30.2 \\
compound 3 & -1185.57131077 & 0.0 & 0.0 & 97.0 \\
3a & -1185.56767675 & 2.34 & 2.06 & 3.0 \\
3b & & & & \\
compound 4 & -1034.09505084 & 0.0 & 0.0 & 48.9 \\
4a & -1034.09466155 & 0.19 & 0.06 & 44.4 \\
$\mathbf{4 b}$ & -1034.09324185 & 1.14 & 1.18 & 6.7 \\
$\mathbf{4 c}$ & & & & \\
\hline
\end{tabular}

${ }^{a}$ From $\Delta G$ values at $298.15 \mathrm{~K}$.

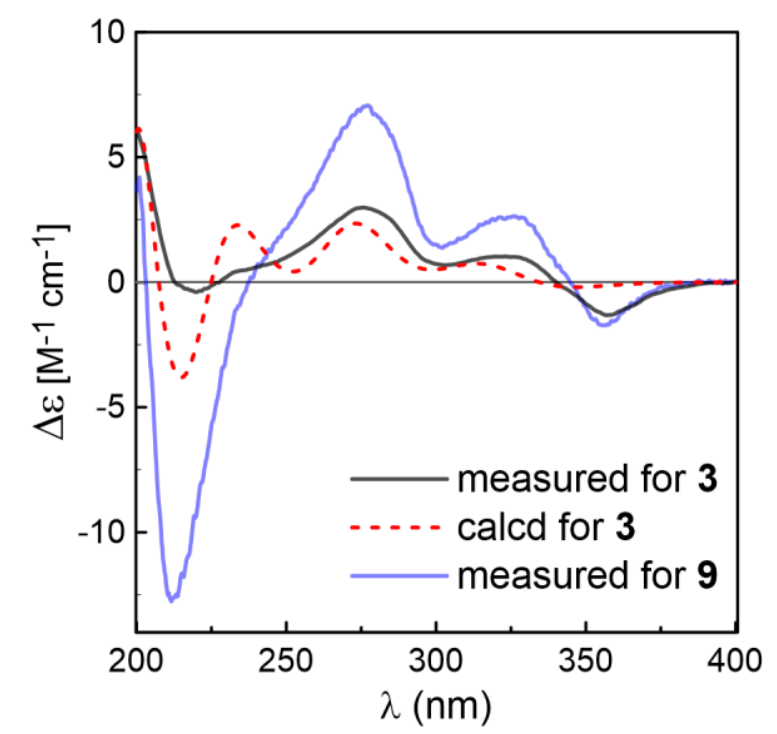

Figure S1. Comparison of the measured ECD spectra of $\mathbf{3}$ and $\mathbf{9}$ with the M06-2X/TZVP/PCM(MeOH) calculated ECD spectrum of $\mathbf{3}(\sigma=0.28$, shift $=+18 \mathrm{~nm})$. 


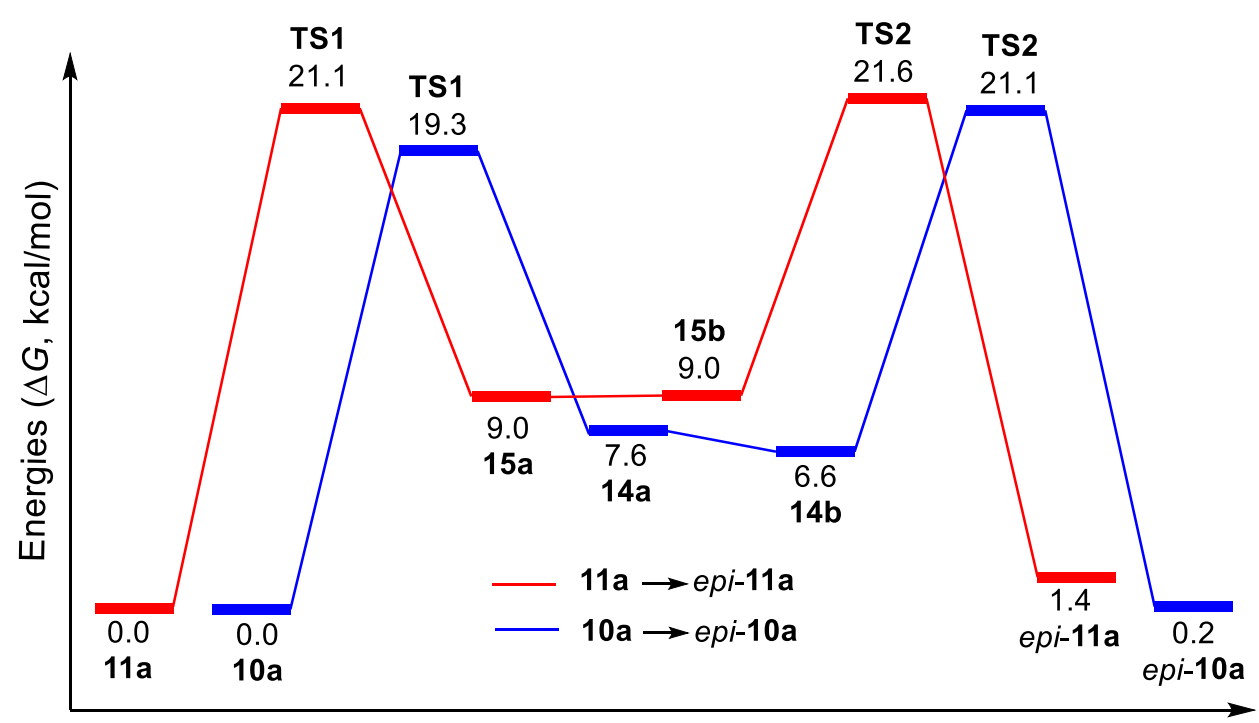

Reaction Coordinate

Figure S2. Reaction coordinate diagrams for C-10a epimerization of 10a (blue line) and 11a (red line).
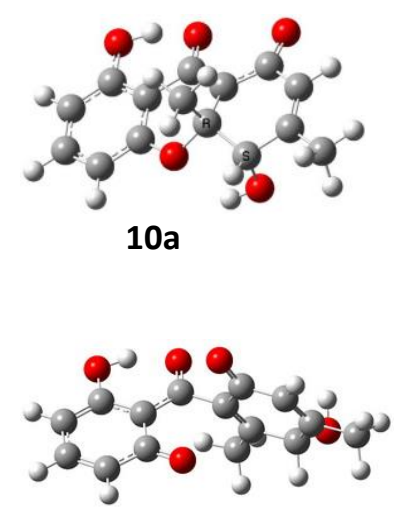

$14 b$

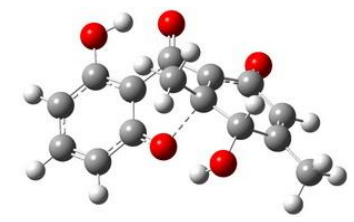

TS1

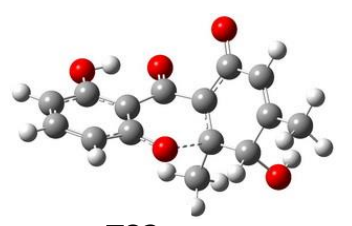

TS2
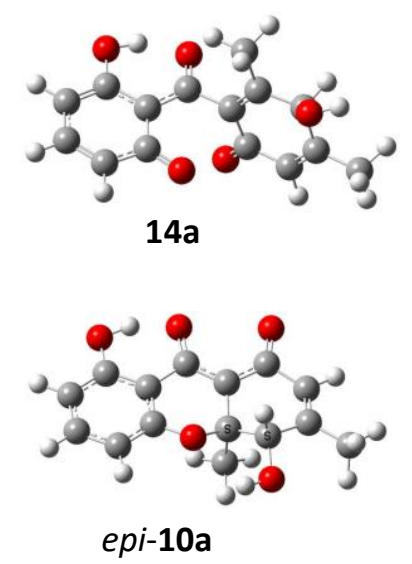

Figure S3. Geometries of the stational points in epimerization of 10a.

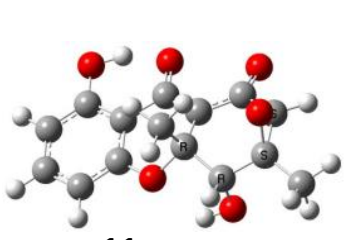

$11 a$

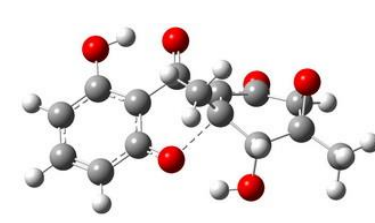

TS1

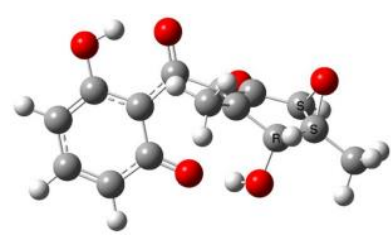

$15 a$

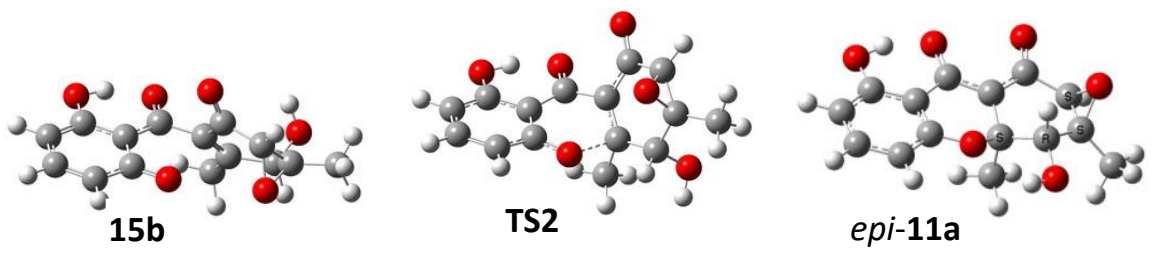

Figure S4. Geometries of the stational points in epimerization of 11a. 

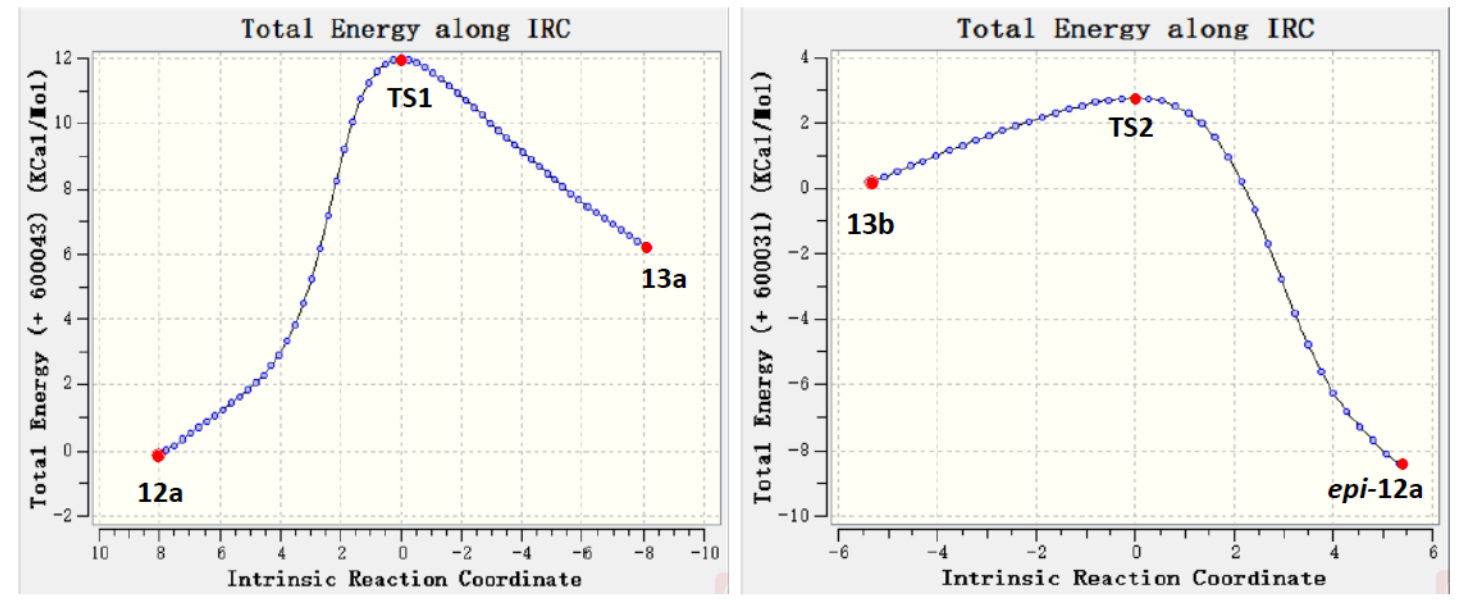

Figure S5. IRC for the C-10a epimerization of 12a
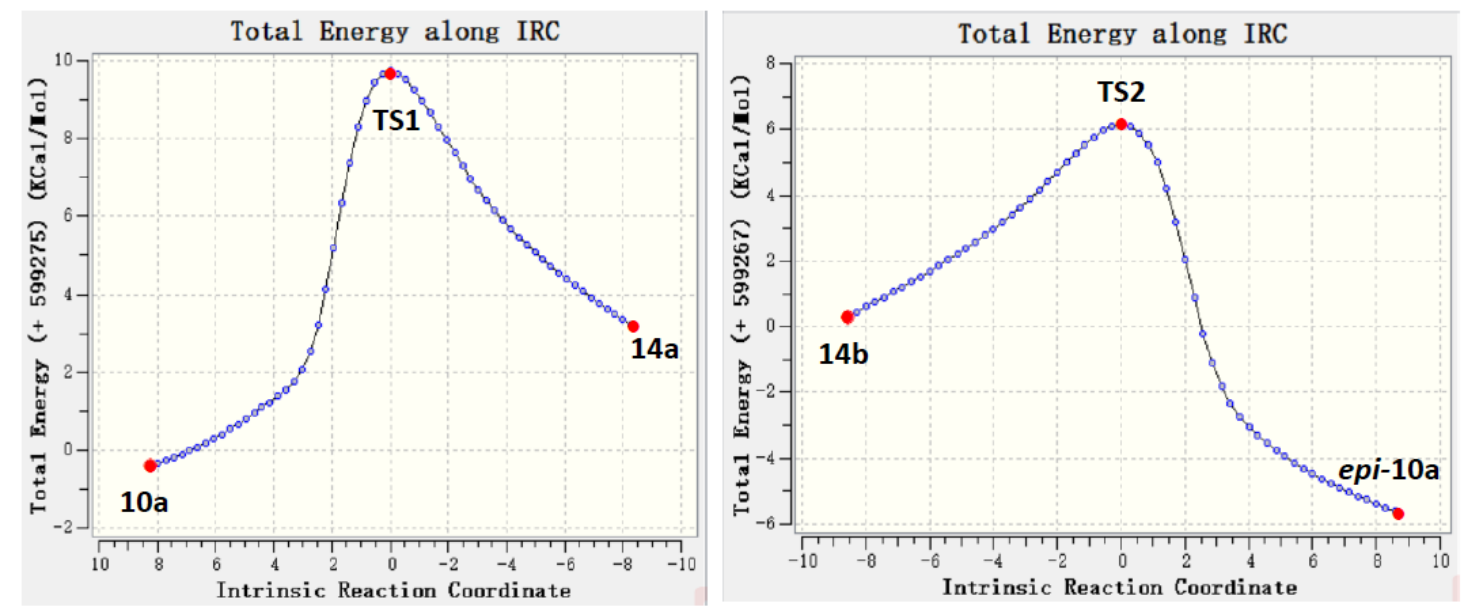

Figure S6. IRC for the C-10a epimerization of $\mathbf{1 0 a}$.
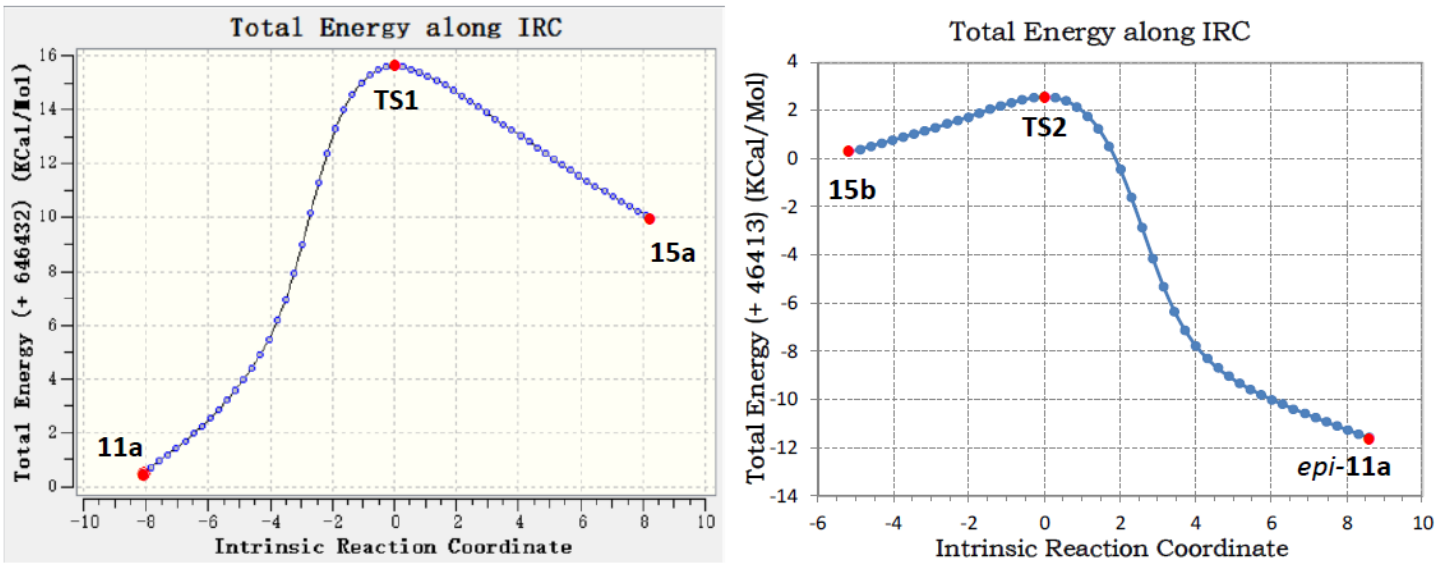

Figure S7. IRC for the C-10a epimerization of 11a. 


\section{References}

(1) Frisch, M. J.; Trucks, G. W.; Schlegel, H. B.; Scuseria, G. E.; Robb, M. A.; Cheeseman, J. R.; Scalmani, G.; Barone, V.; Mennucci, B.; Petersson, G. A.; Nakatsuji, H.; Caricato, M.; Li, X.; Hratchian, H. P.; Izmaylov, A. F.; Bloino, J.; Zheng, G.; Sonnenberg, J. L.; Hada, M.; Ehara, M.; Toyota, K.; Fukuda, R.; Hasegawa, J.; Ishida, M.; Nakajima, T.; Honda, Y.; Kitao, O.; Nakai, H.; Vreven, T.; Montgomery, J. A.; Peralta, J. E.; Ogliaro, F.; Bearpark, M.; Heyd, J. J.; Brothers, E.; Kudin, K. N.; Staroverov, V. N.; Keith, T.; Kobayashi, R.; Normand, J.; Raghavachari, K.; Rendell, A.; Burant, J. C.; Iyengar, S. S.; Tomasi, J.; Cossi, M.; Rega, N.; Millam, J. M.; Klene, M.; Knox, J. E.; Cross, J. B.; Bakken, V.; Adamo, C.; Jaramillo, J.; Gomperts, R.; Stratmann, R. E.; Yazyev, O.; Austin, A. J.; Cammi, R.; Pomelli, C.; Ochterski, J. W.; Martin, R. L.; Morokuma, K.; Zakrzewski, V. G.; Voth, G. A.; Salvador, P.; Dannenberg, J. J.; Dapprich, S.; Daniels, A. D.; Farkas, O.; Foresman, J. B.; Ortiz, J. V.; Cioslowski, J.; Fox, D. J. Gaussian 09, revision D.01. Gaussian, Inc.: Wallingford CT, 2013.

(2) Neese, F. WIREs: Comput. Molecul. Sci. 2012, 2(1), 73-78; 2017, 8(1), e1327.

(3) (a) Becke, A. D. J. Chem. Phys. 1993, 98, 5648-5652. (b) Becke, A. D. Phys. Rev. A: At., Mol., Opt. Phys. 1988, 38, 3098-3100. (c) Lee, T.; Yang, W. T.; Parr, R. G. Phys. Rev. B: Condens. Matter Mater. Phys. 1988, 37, 785-789.

(4) Zhao, Y.; Truhlar, D. G. Theor. Chem. Acc. 2008, 120, 215-241.

(5) (a) Schäfer, A.; Horn, H.; Ahlrichs, R. J. Chem. Phys. 1992, 97, 2571-77. (b) Schäfer, A.; Huber, C.; Ahlrichs, R. J. Chem. Phys. 1994, 100, 5829-5835.

(6) Bruhn, T.; Schaumlöffel, A.; Hemberger, Y.; Bringmann, G. Chirality 2013, 25, 243-249.

(7) (a) Grimme, S.; Antony, J.; Ehrlich, S.; Krieg, H. J. Chem. Phys. 2010, 132, 154104. (b) Grimme,S.; Ehrlich, S.; Goerigk, L. J. Comput. Chem. 2011, 32, 1456-1465.

(8) Weigend, F.; Ahlrichs, R. Phys. Chem. Chem. Phys. 2005, 7, 3297-3305.

(9) Goerigk, L.; Grimme, S. J. Chem. Theory Comput. 2011, 7, 291-309.

(10) Weigend, F.; Ahlrichs, R. Phys. Chem. Chem. Phys. 2005, 7, 3297-3305.

(11) Marenich, A. V.; Cramer, C. J.; Truhlar D. G. J. Phys. Chem. B 2009, 113, 6378-6396. 


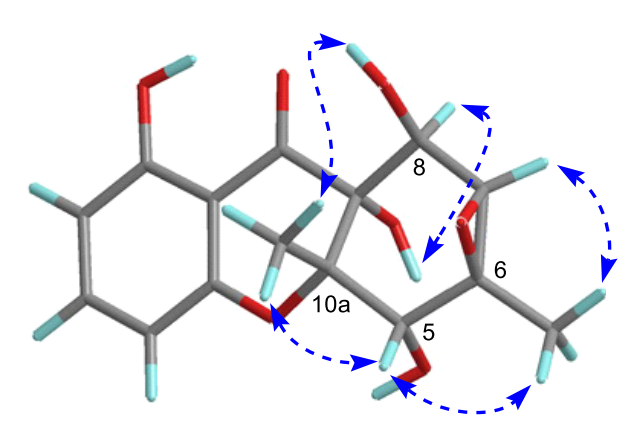

1

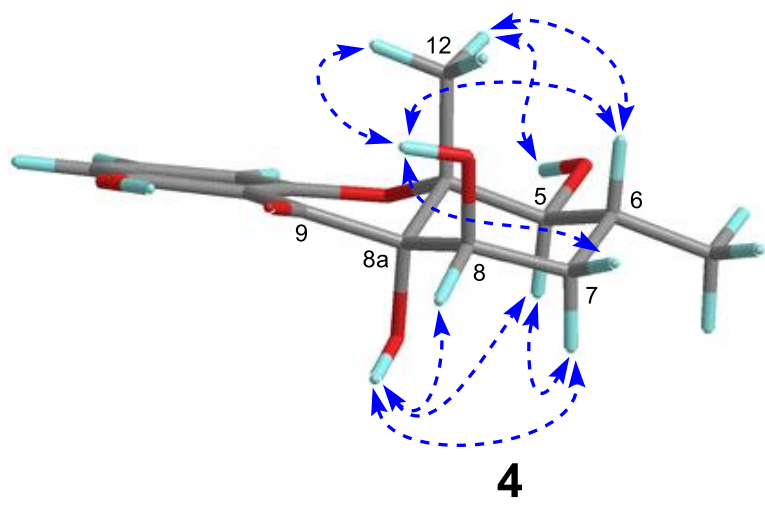

Figure S8. Key NOE correlations in NOESY spectra of $\mathbf{1}$ and $\mathbf{4}$ in DMSO- $d_{6}$

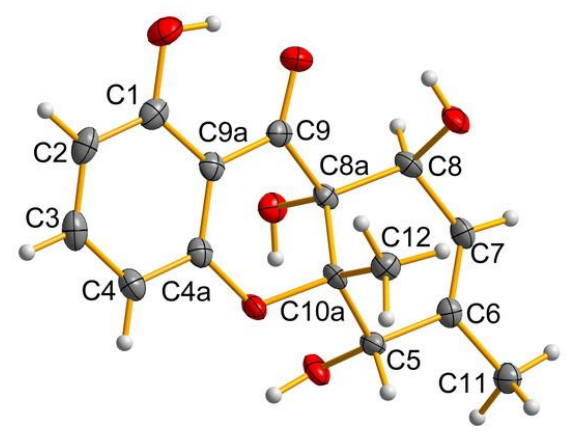

Figure S9. X-ray structure of 9. Flack parameter: -0.04(15) 


\section{NMR Spectra of 1-8}

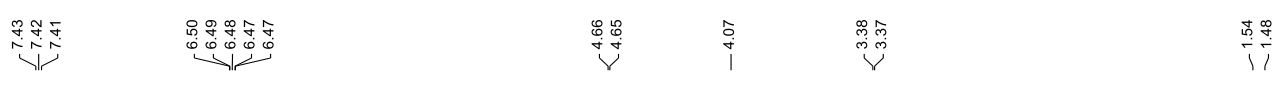<smiles>CC12OC1[C@@H](O)[C@@]1(O)C(=O)c3c(O)cccc3O[C@@]21C</smiles>

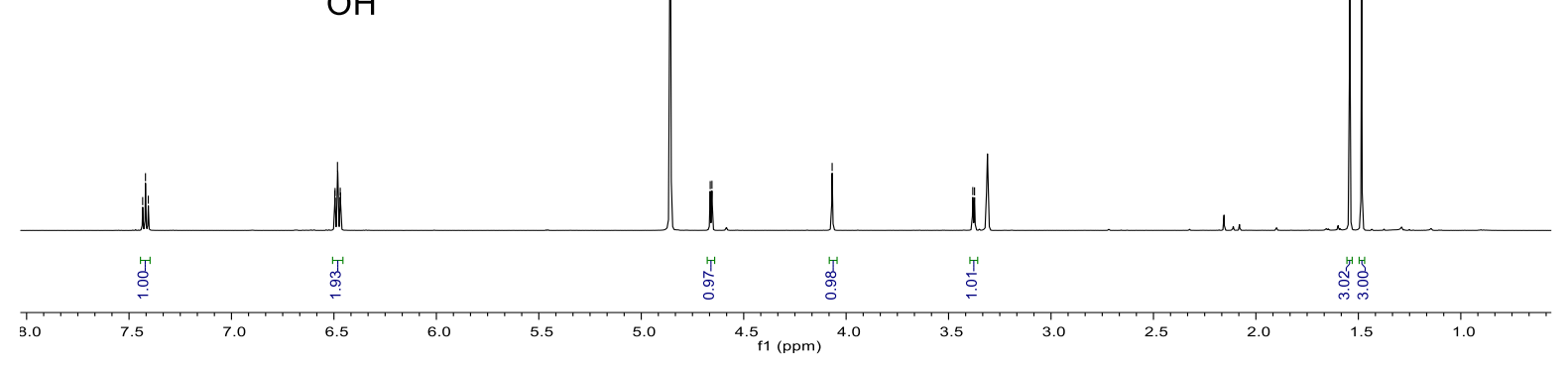

Figure S10. ${ }^{1} \mathrm{H}$ NMR spectrum of penicixanthone $\mathrm{A}(\mathbf{1})$ in $\mathrm{CD}_{3} \mathrm{OD}$.<smiles>CC12OC1[C@@H](O)[C@@]1(C)Oc3cccc(O)c3C(=O)[C@]1(O)[C@H]2O</smiles>

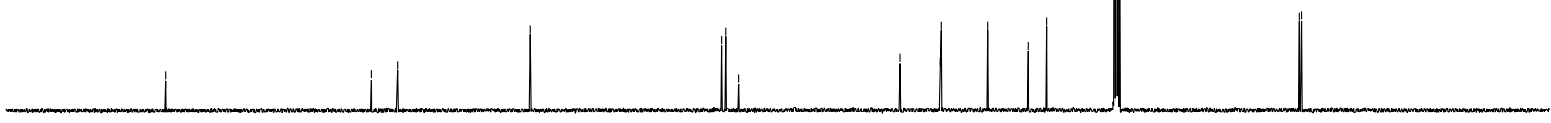

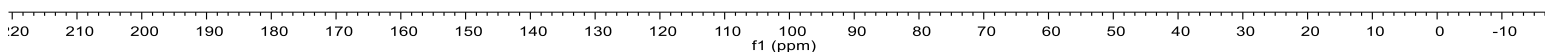

Figure S11. ${ }^{13} \mathrm{C}$ NMR spectrum of penicixanthone $\mathrm{A}(\mathbf{1})$ in $\mathrm{CD}_{3} \mathrm{OD}$. 


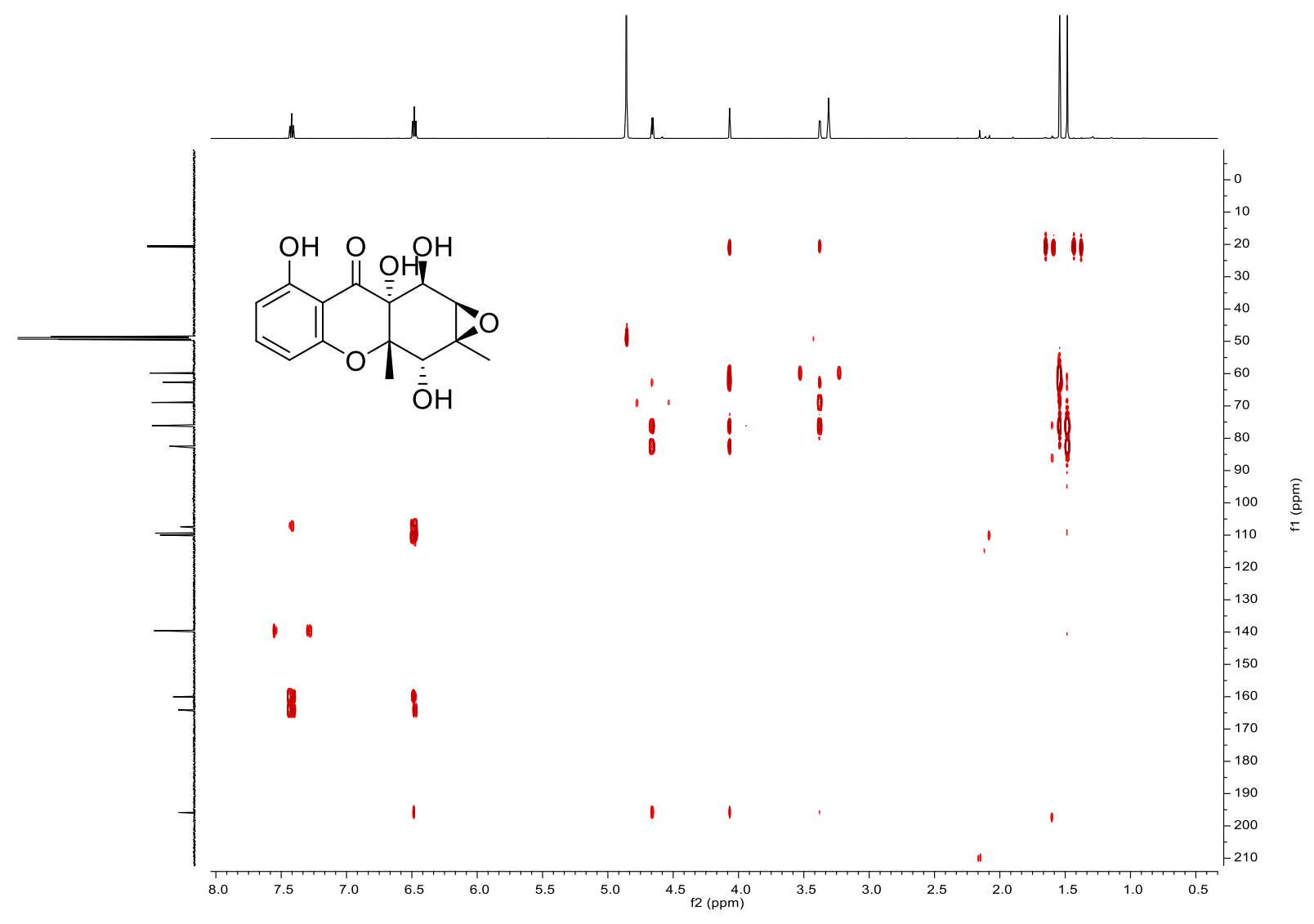

Figure S12. HMBC NMR of penicixanthone $\mathrm{A}(\mathbf{1})$ in $\mathrm{CD}_{3} \mathrm{OD}$.

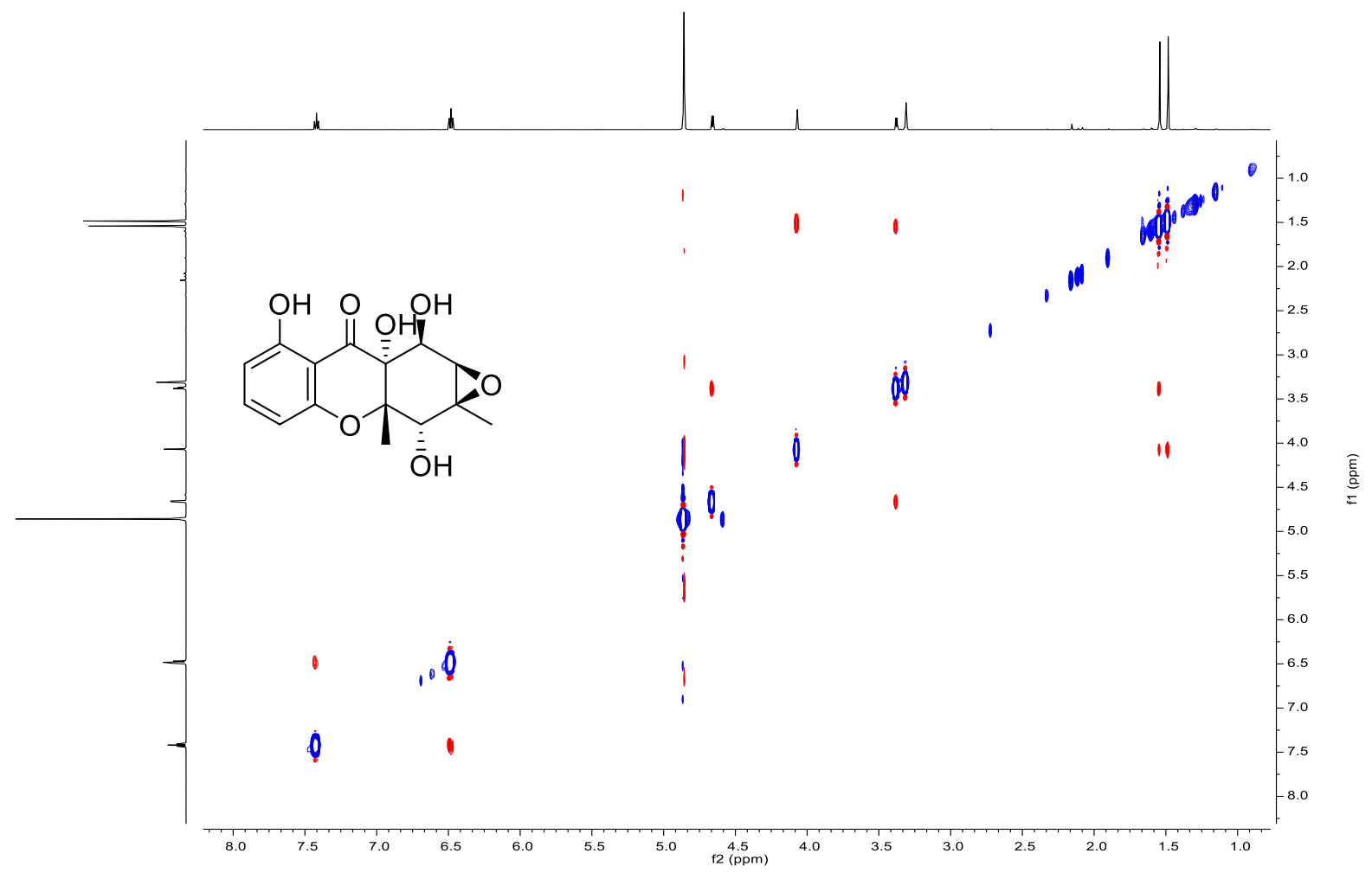

Figure S13. NOESY NMR of penicixanthone A (1) in $\mathrm{CD}_{3} \mathrm{OD}$. 


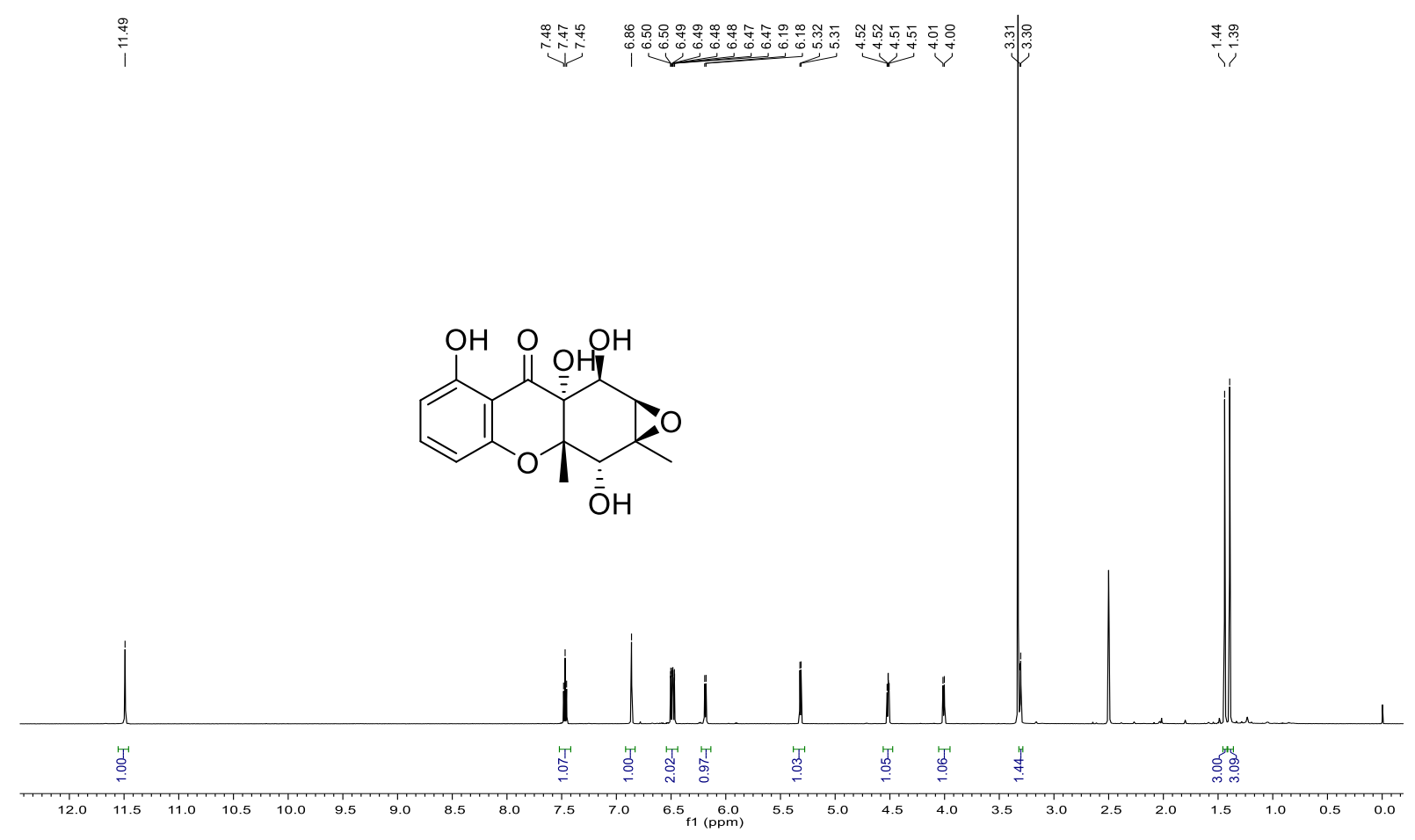

Figure S14. ${ }^{1} \mathrm{H}$ NMR spectrum of penicixanthone A (1) in DMSO- $d_{6}$.

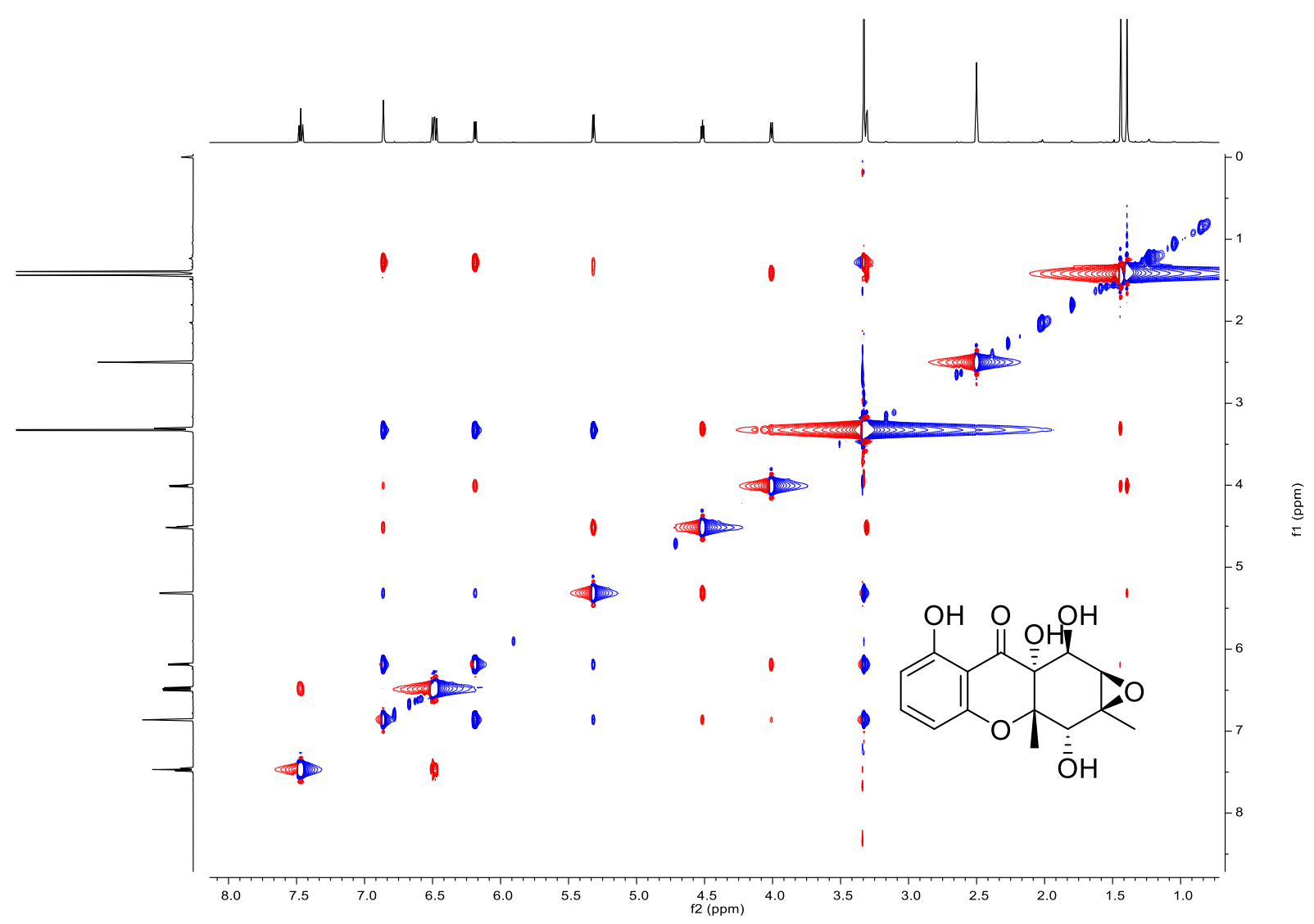

Figure S15. NOESY NMR of penicixanthone A (1) in DMSO- $d_{6}$. 


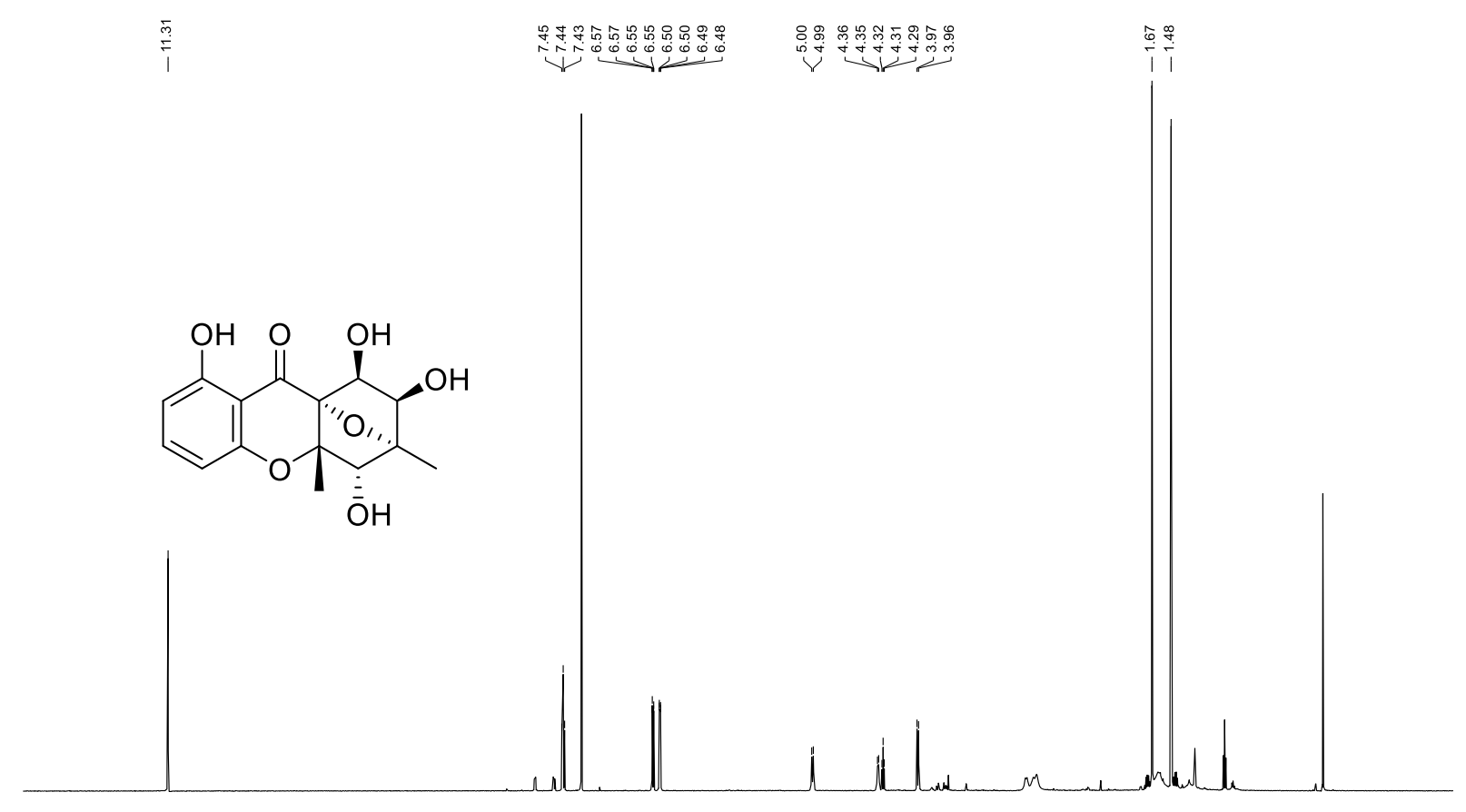

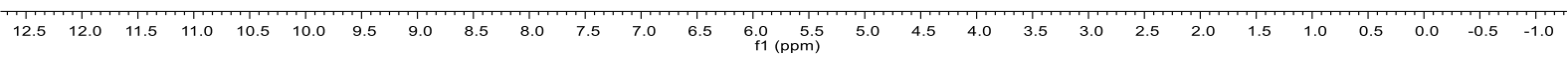

Figure S16. ${ }^{1} \mathrm{H}$ NMR spectrum of penicixanthone B (2) in $\mathrm{CDCl}_{3}$.

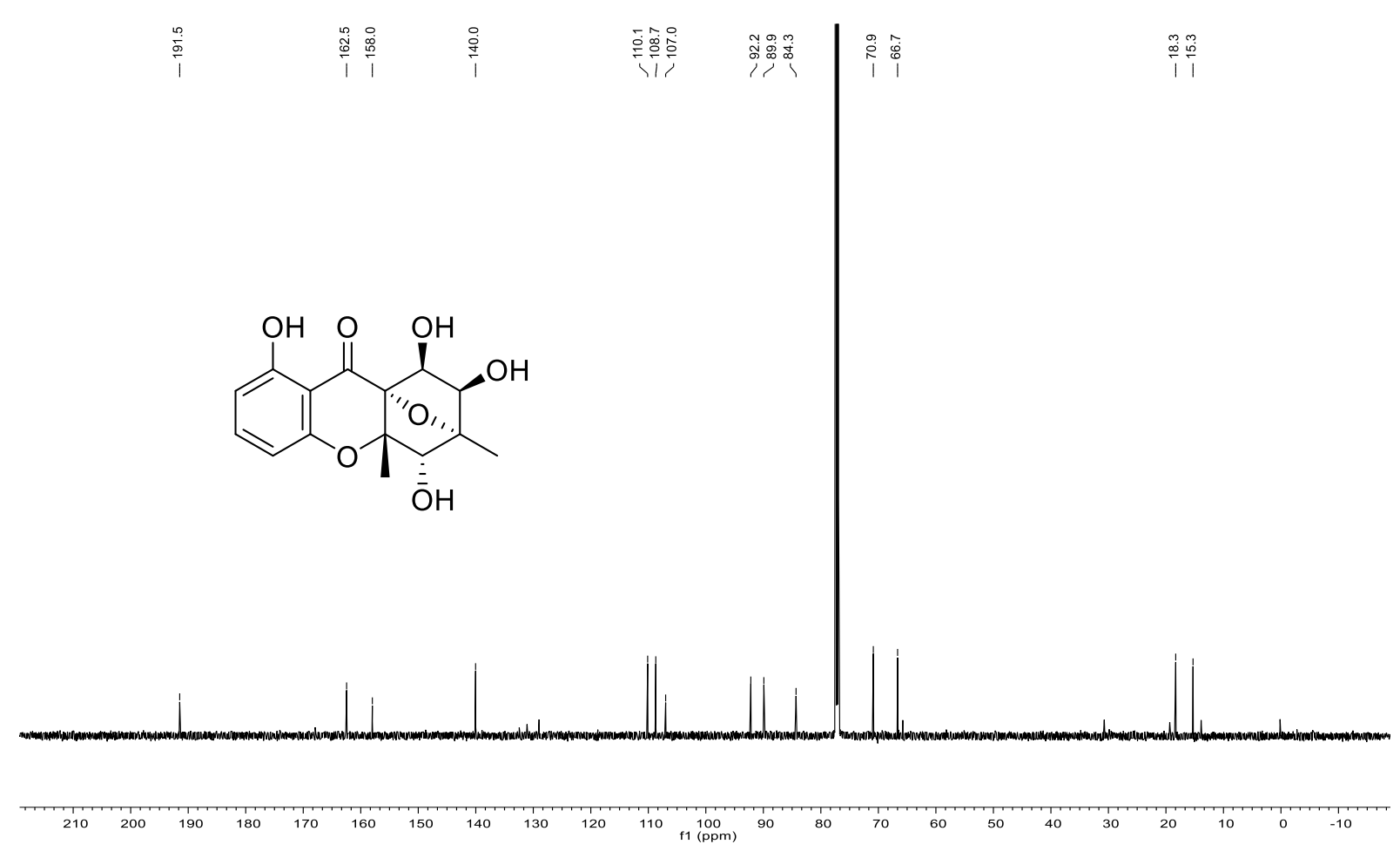

Figure S17. ${ }^{13} \mathrm{C}$ NMR spectrum of penicixanthone B (2) in $\mathrm{CDCl}_{3}$. 


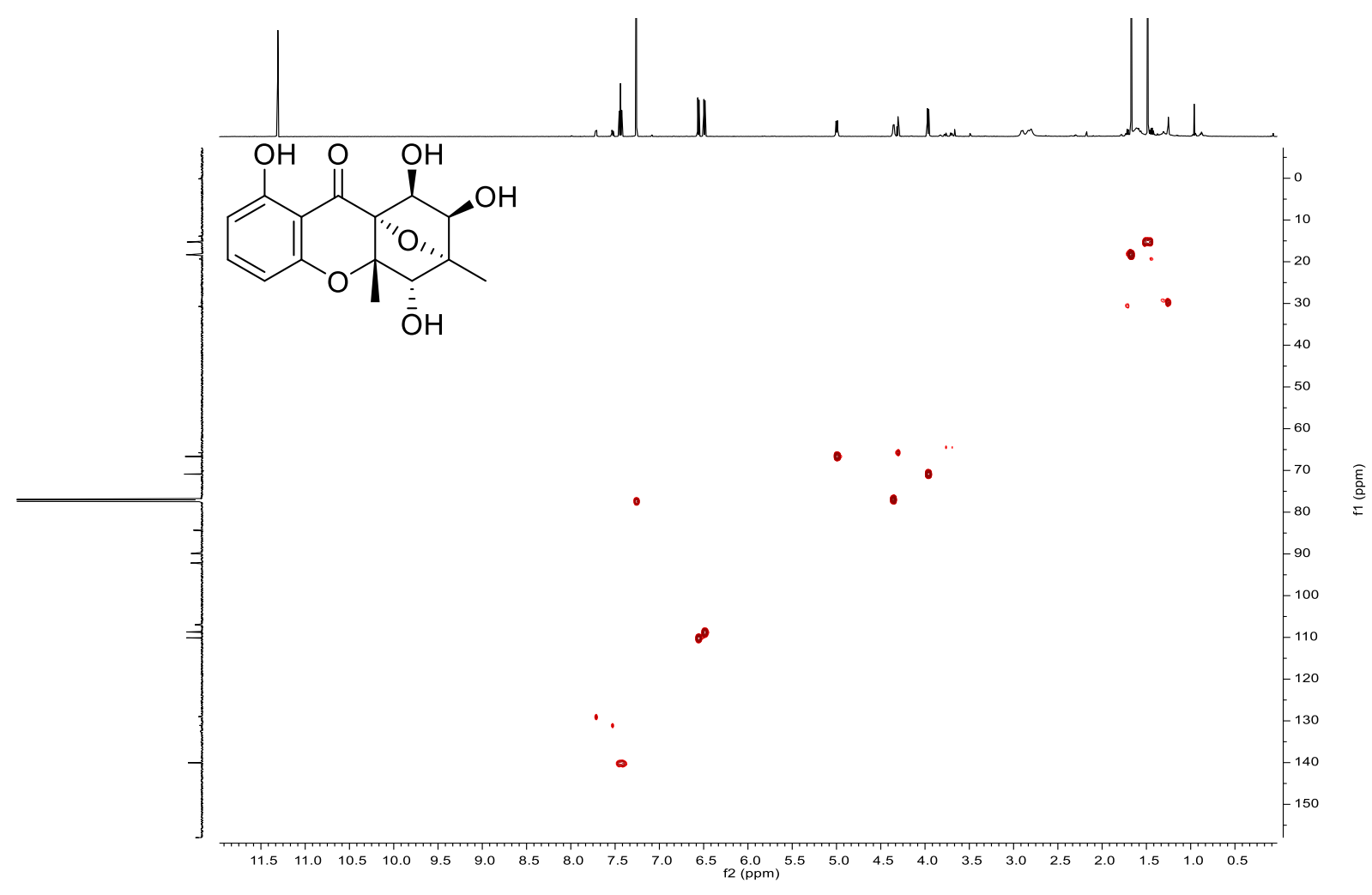

Figure S18. HSQC NMR of penicixanthone B (2) in $\mathrm{CDCl}_{3}$.

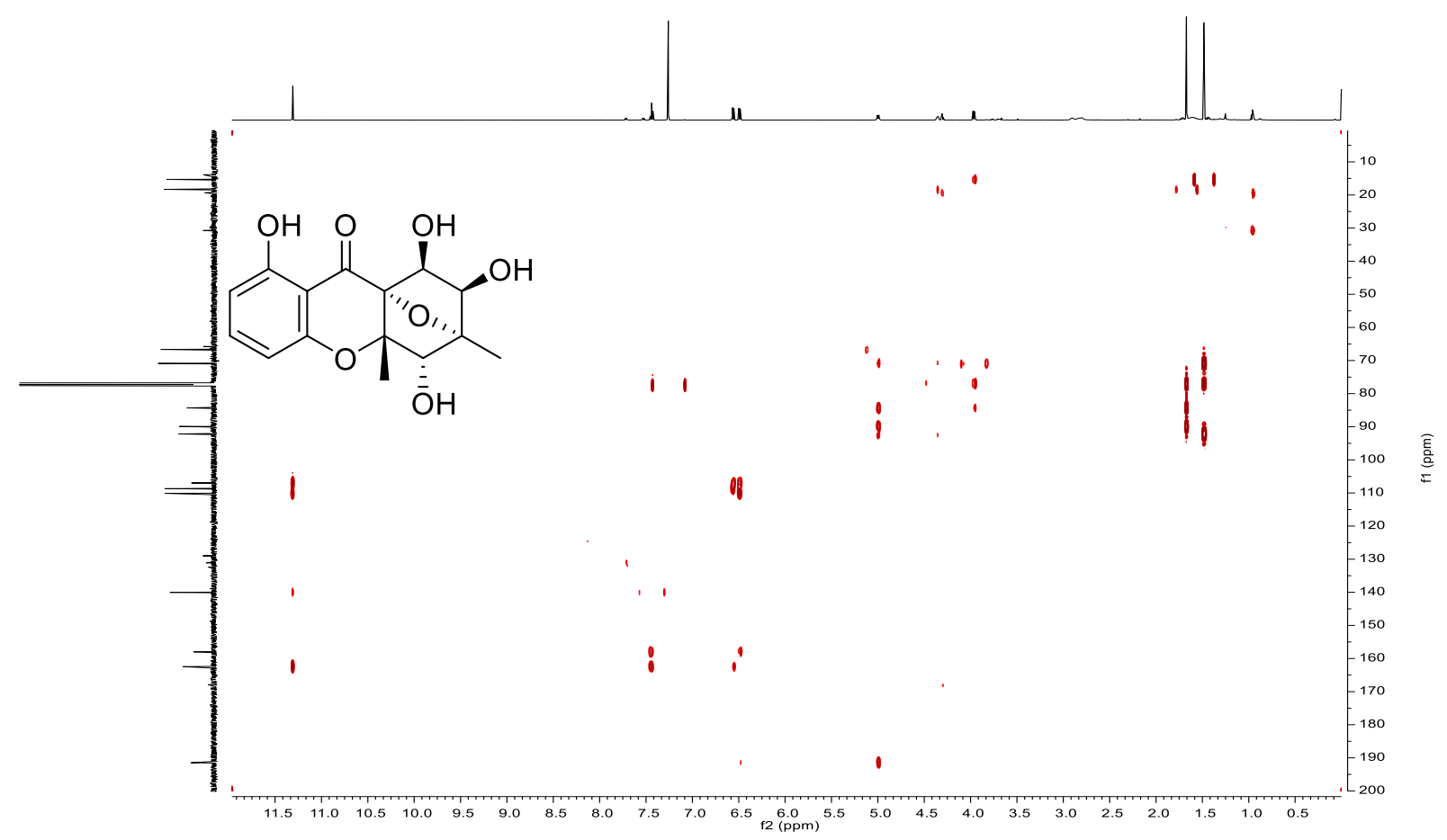

Figure S19. HMBC NMR of penicixanthone B (2) in $\mathrm{CDCl}_{3}$. 


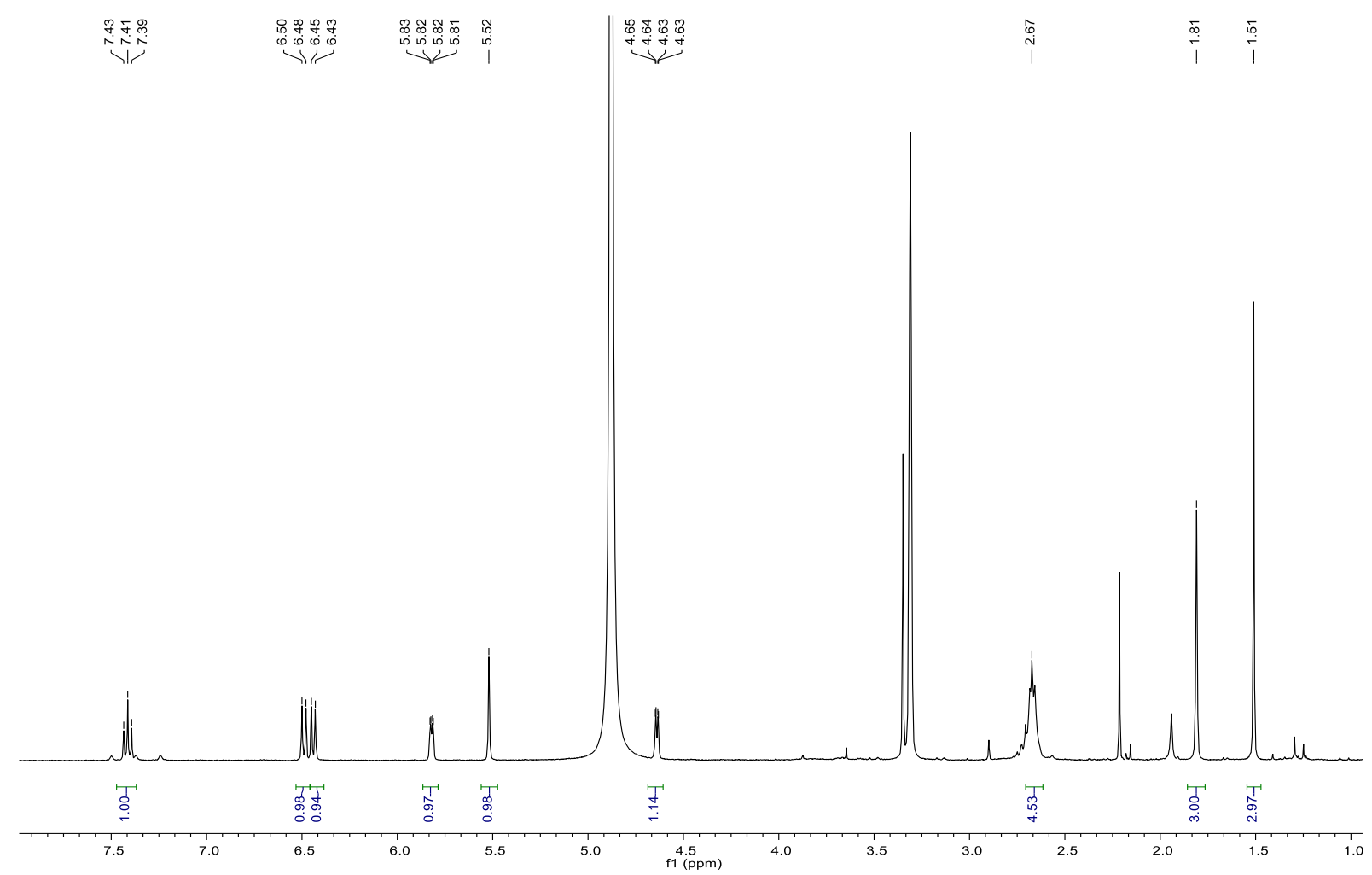

Figure S20. ${ }^{1} \mathrm{H}$ NMR spectrum of penicixanthone $\mathrm{C}(\mathbf{3})$ in $\mathrm{CD}_{3} \mathrm{OD}$.

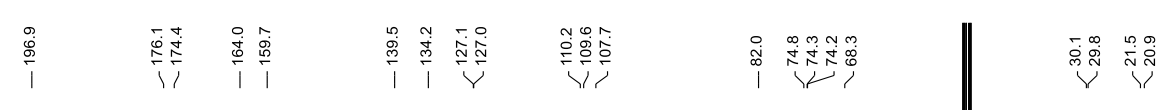<smiles>CC1=CC(O)[C@]2(O)C(=O)c3c(O)cccc3O[C@]2(C)C1OC(=O)CCC(=O)O</smiles>

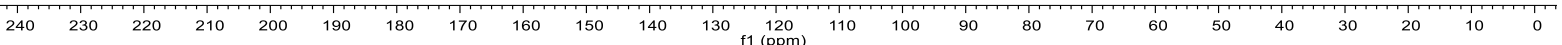

Figure S21. ${ }^{13} \mathrm{C}$ NMR spectrum of penicixanthone $\mathrm{C}(\mathbf{3})$ in $\mathrm{CD}_{3} \mathrm{OD}$. 


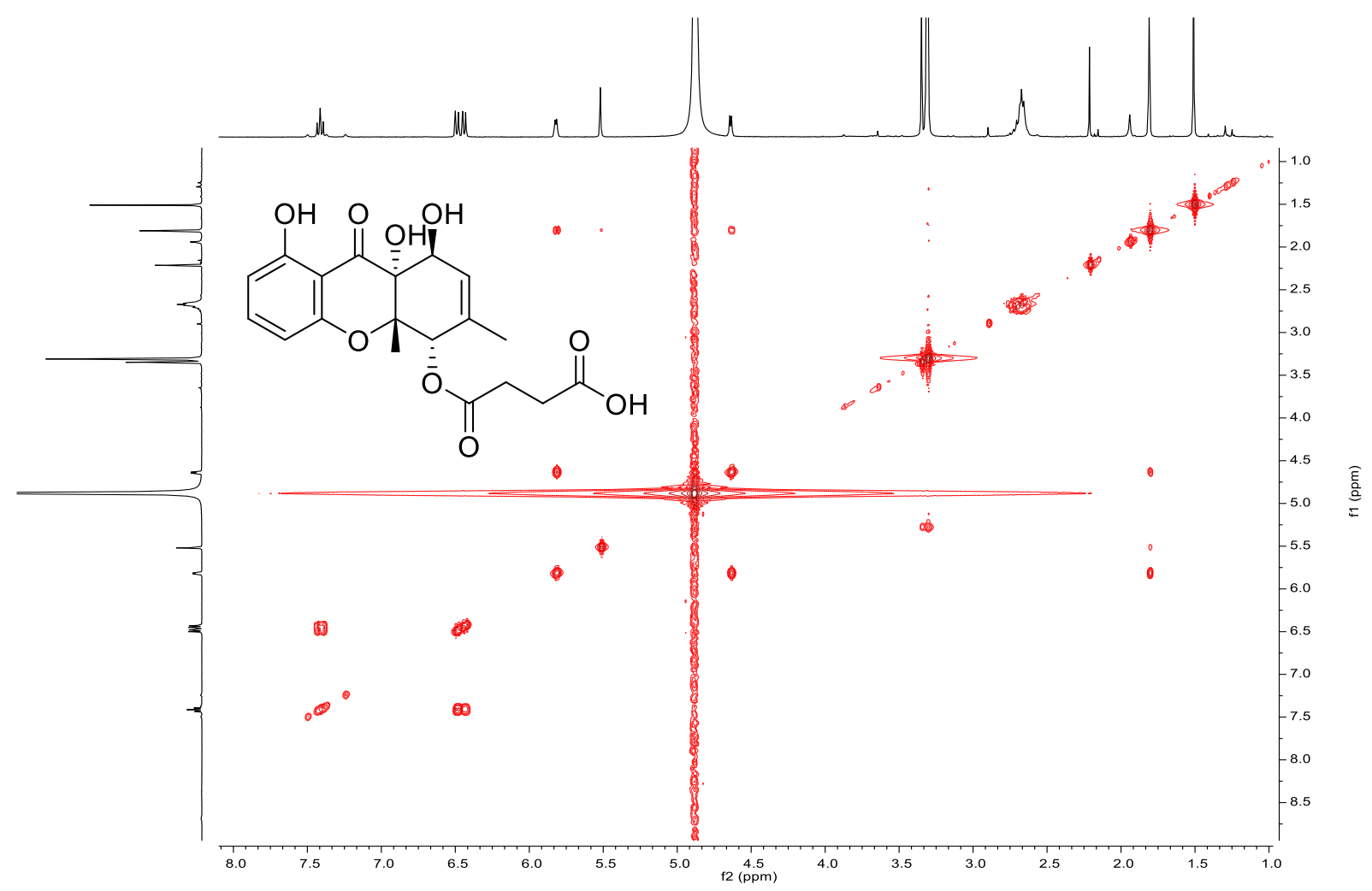

Figure S22. ${ }^{1} \mathrm{H}-{ }^{1} \mathrm{H}$ COSY NMR spectrum of penicixanthone $\mathrm{C}(\mathbf{3})$ in $\mathrm{CD}_{3} \mathrm{OD}$.

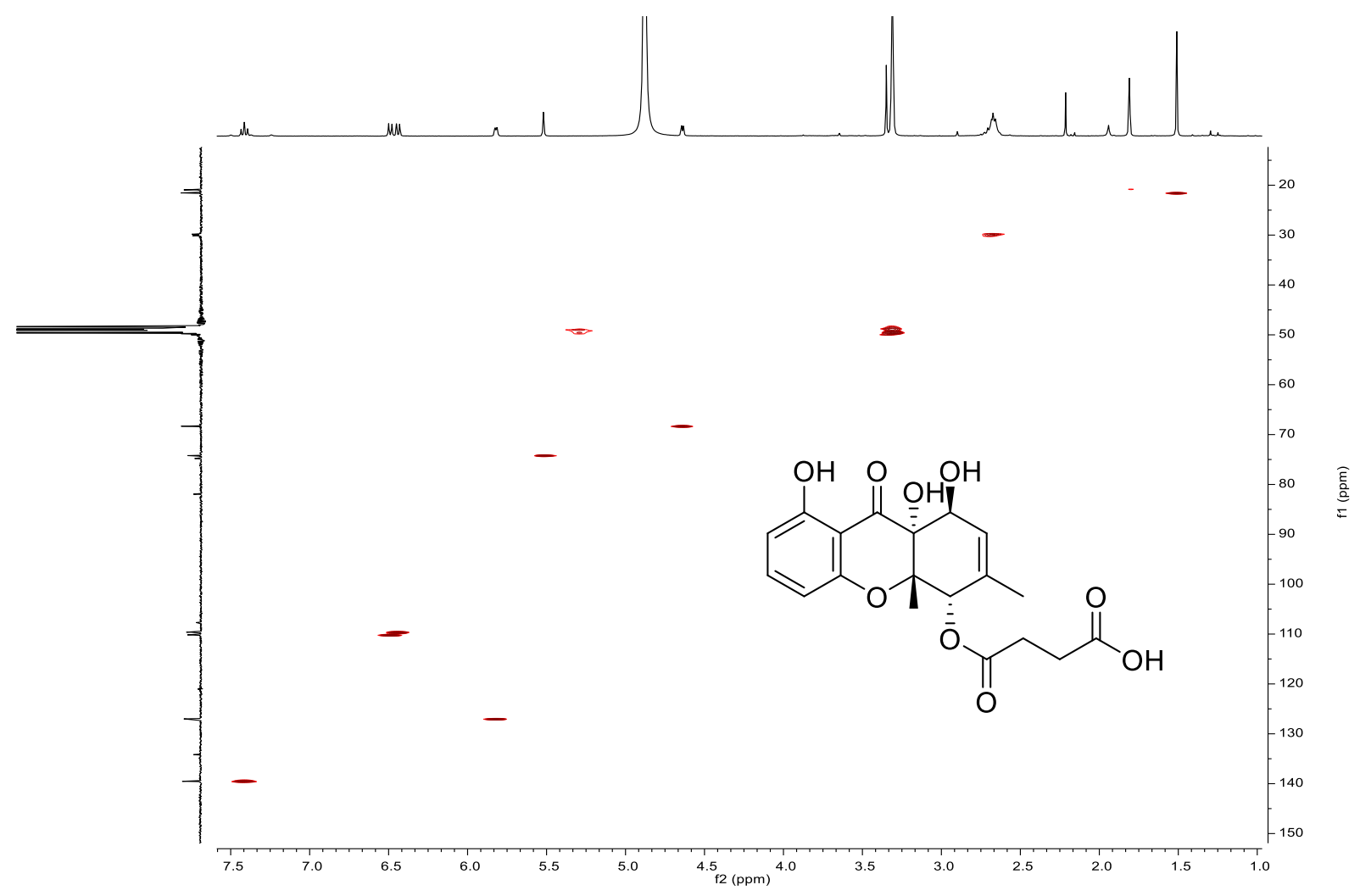

Figure S23. HSQC NMR of penicixanthone $\mathrm{C}(\mathbf{3})$ in $\mathrm{CD}_{3} \mathrm{OD}$. 


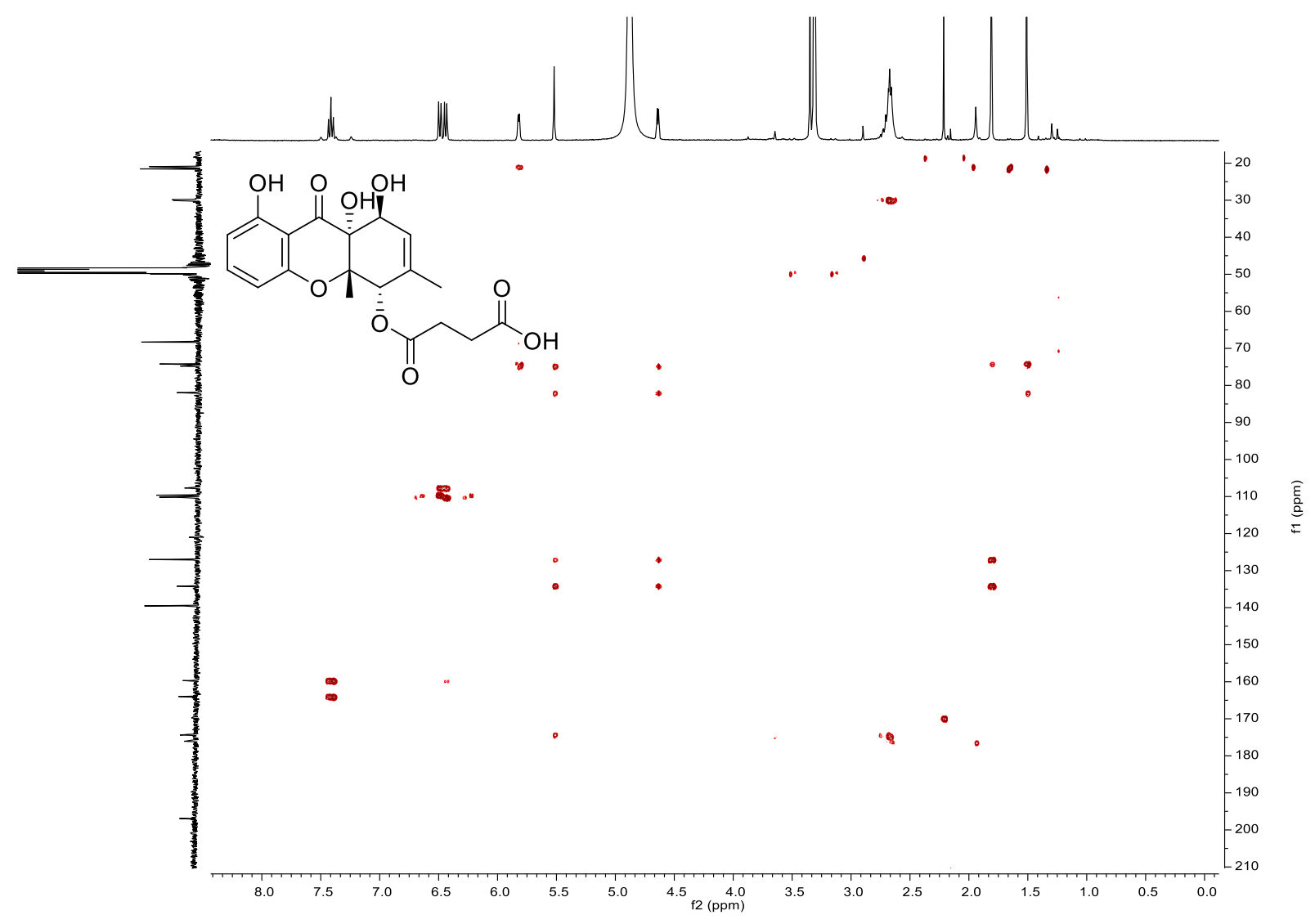

Figure S24. HMBC NMR of penicixanthone C (3) in $\mathrm{CD}_{3} \mathrm{OD}$.

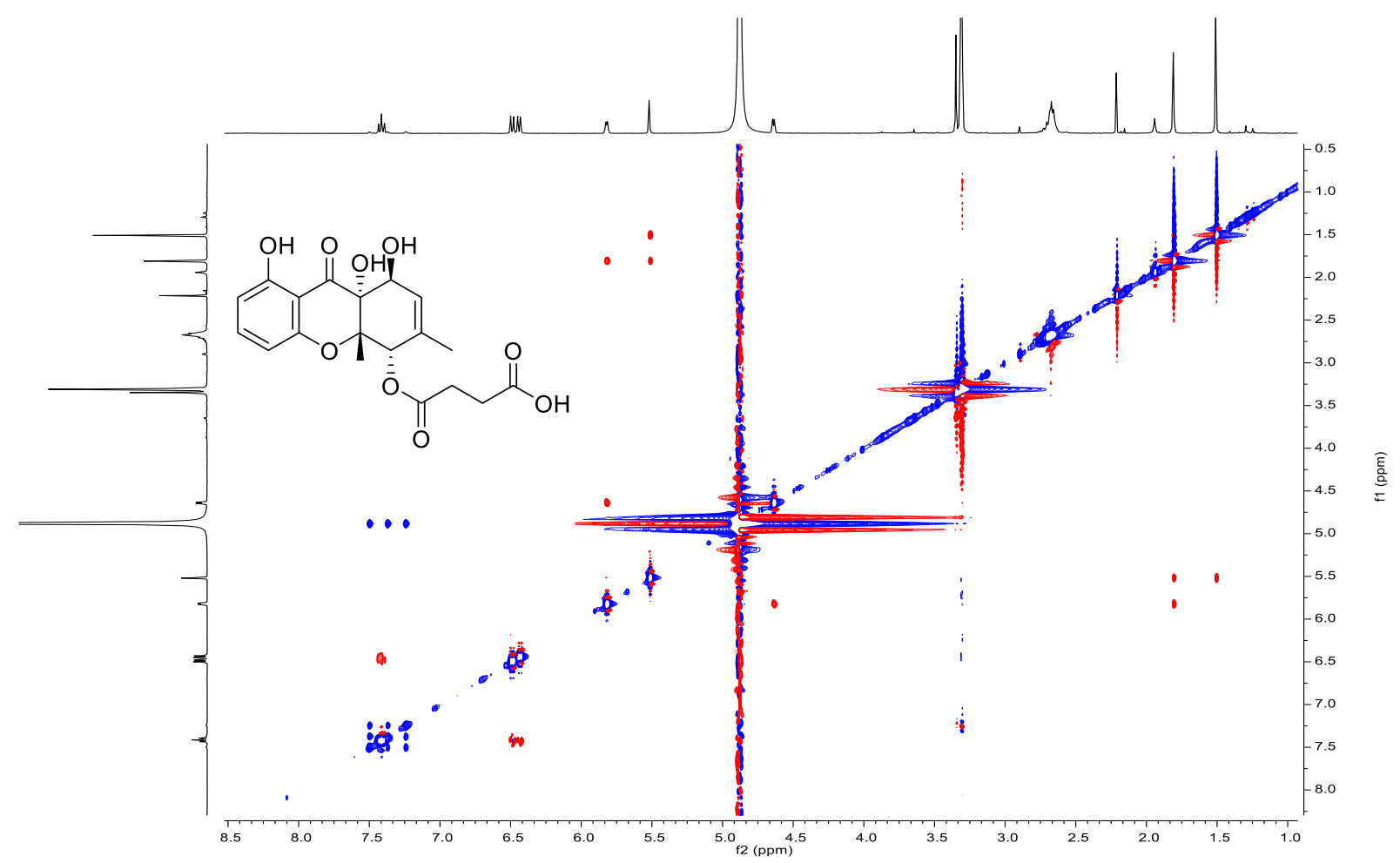

Figure S25. NOESY NMR of penicixanthone C (3) in $\mathrm{CD}_{3} \mathrm{OD}$. 


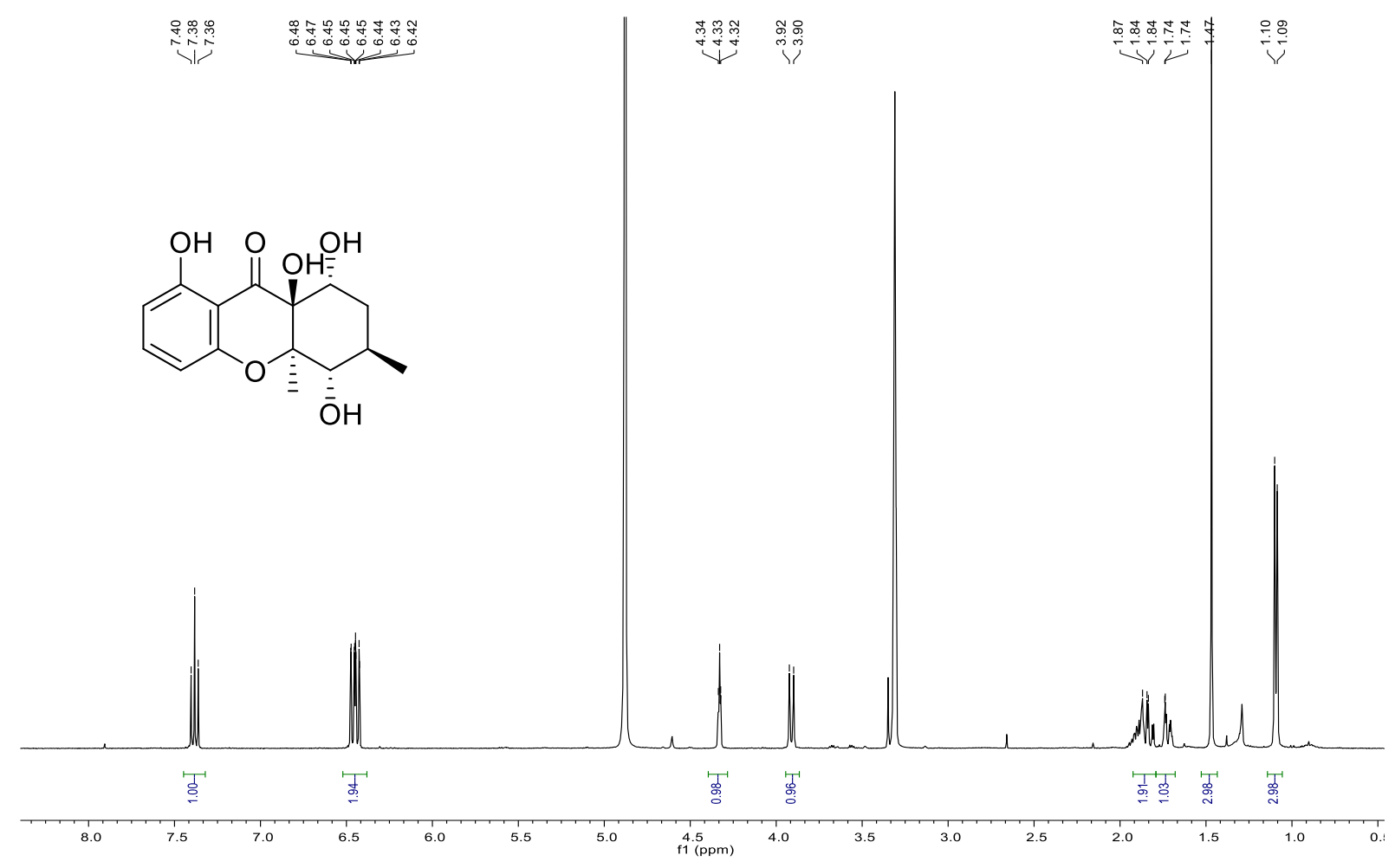

Figure S26. ${ }^{1} \mathrm{H}$ NMR spectrum of penicixanthone D (4) in $\mathrm{CD}_{3} \mathrm{OD}$.

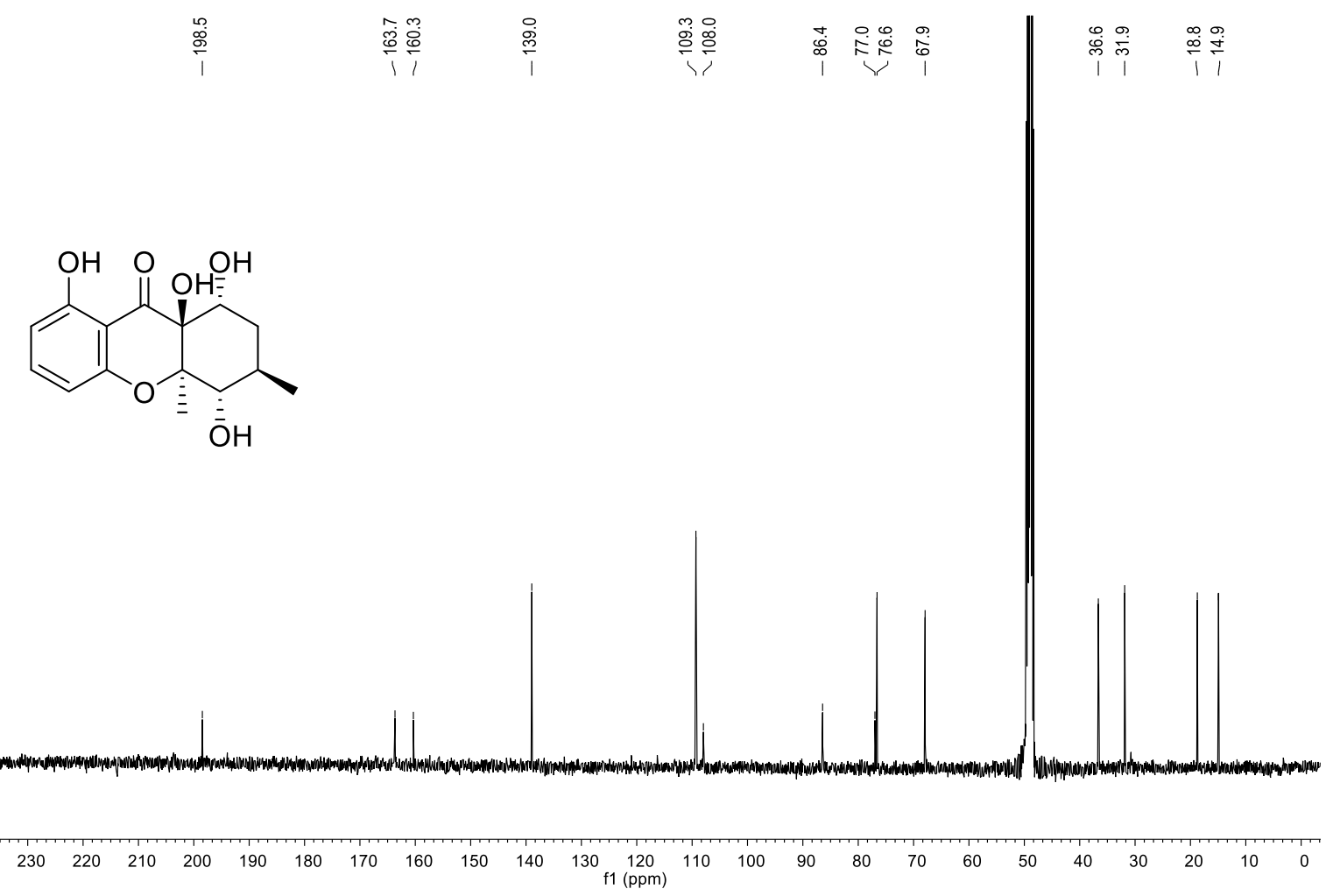

Figure S27. ${ }^{13} \mathrm{C}$ NMR spectrum of penicixanthone $\mathrm{D}(4)$ in $\mathrm{CD}_{3} \mathrm{OD}$. 


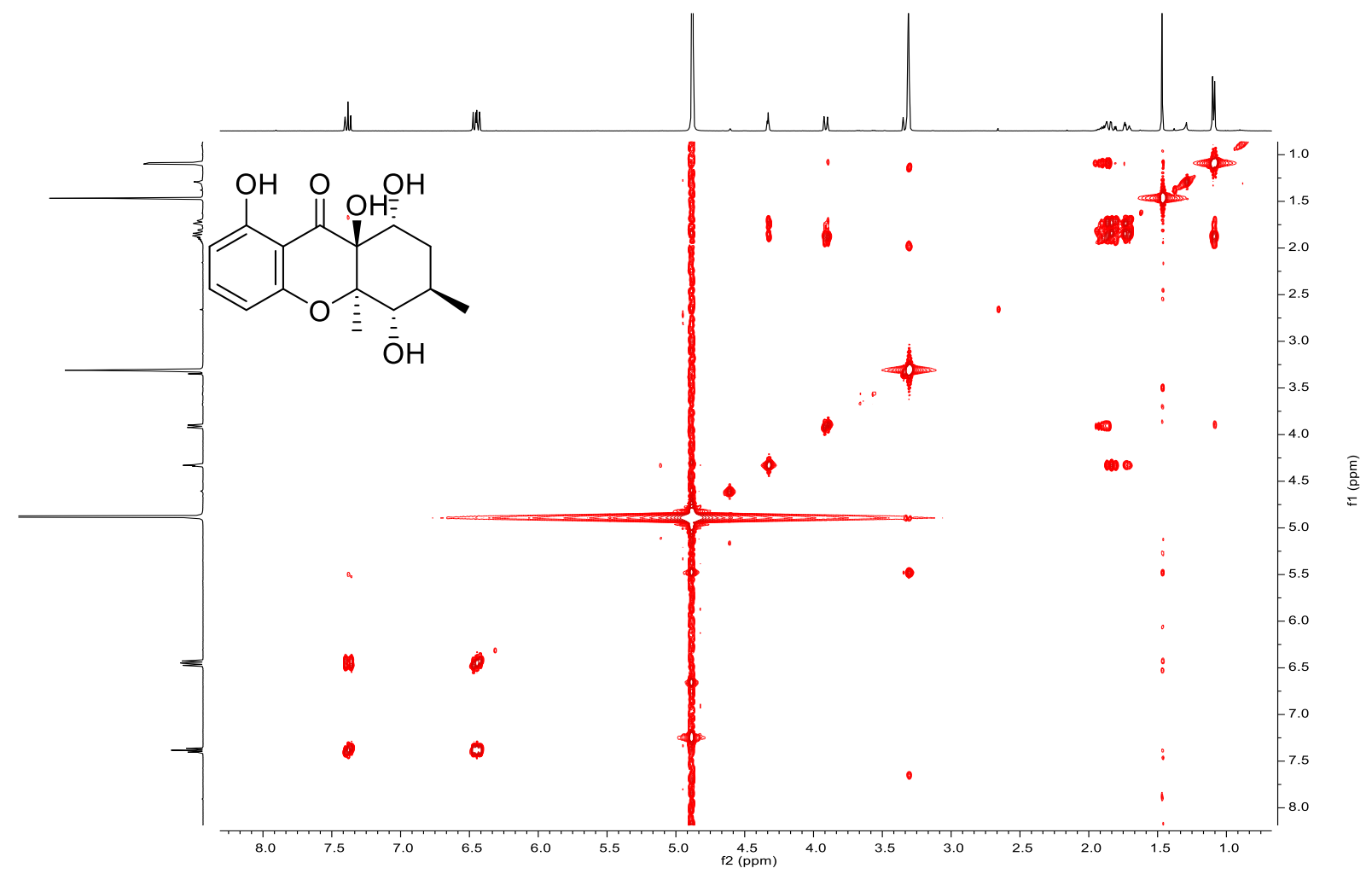

Figure S28. ${ }^{1} \mathrm{H}-{ }^{1} \mathrm{H}$ COSY NMR spectrum of penicixanthone D (4) in $\mathrm{CD}_{3} \mathrm{OD}$.

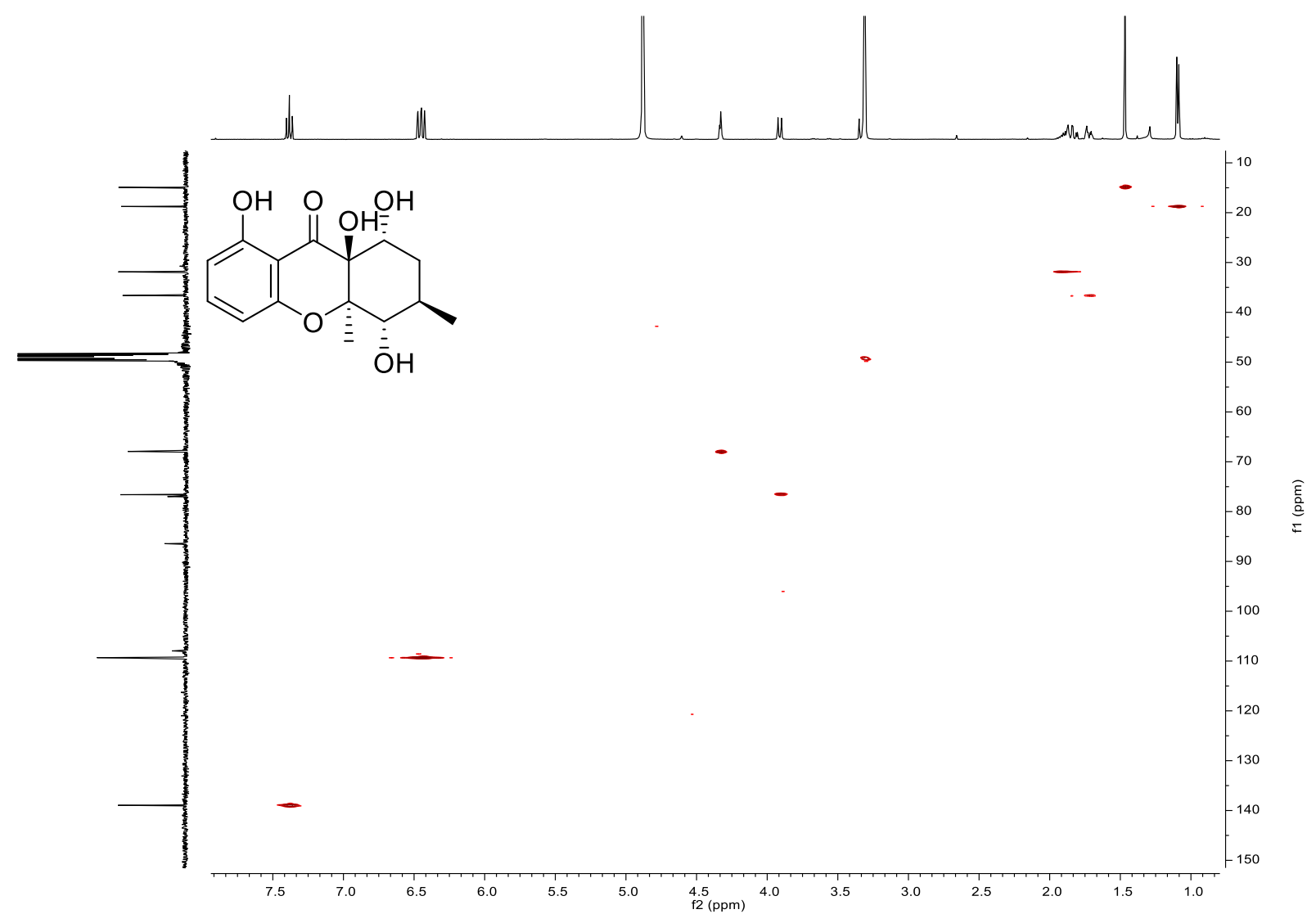

Figure S29. HSQC NMR of penicixanthone D (4) in $\mathrm{CD}_{3} \mathrm{OD}$. 


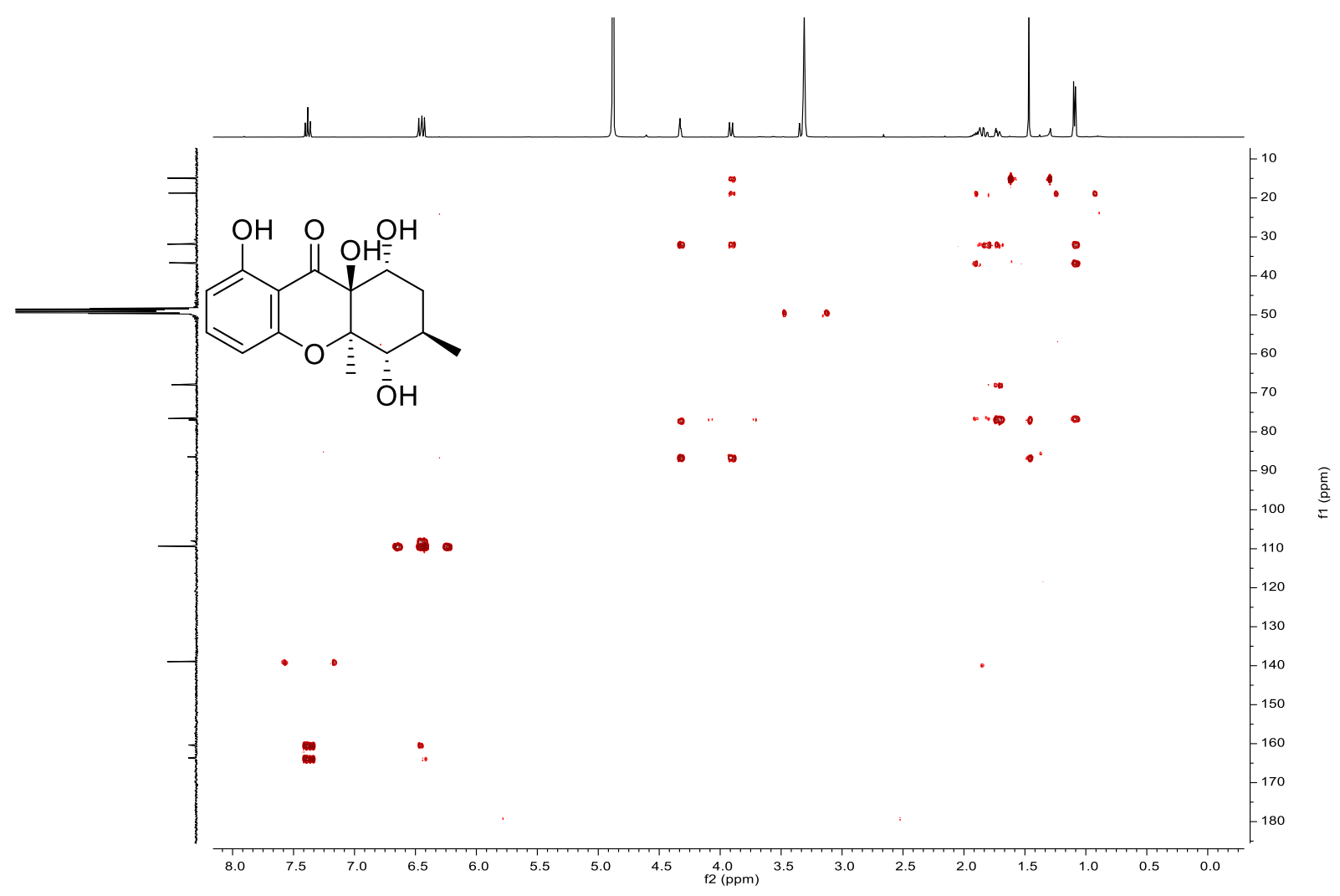

Figure S30. HMBC NMR of penicixanthone D (4) in $\mathrm{CD}_{3} \mathrm{OD}$.

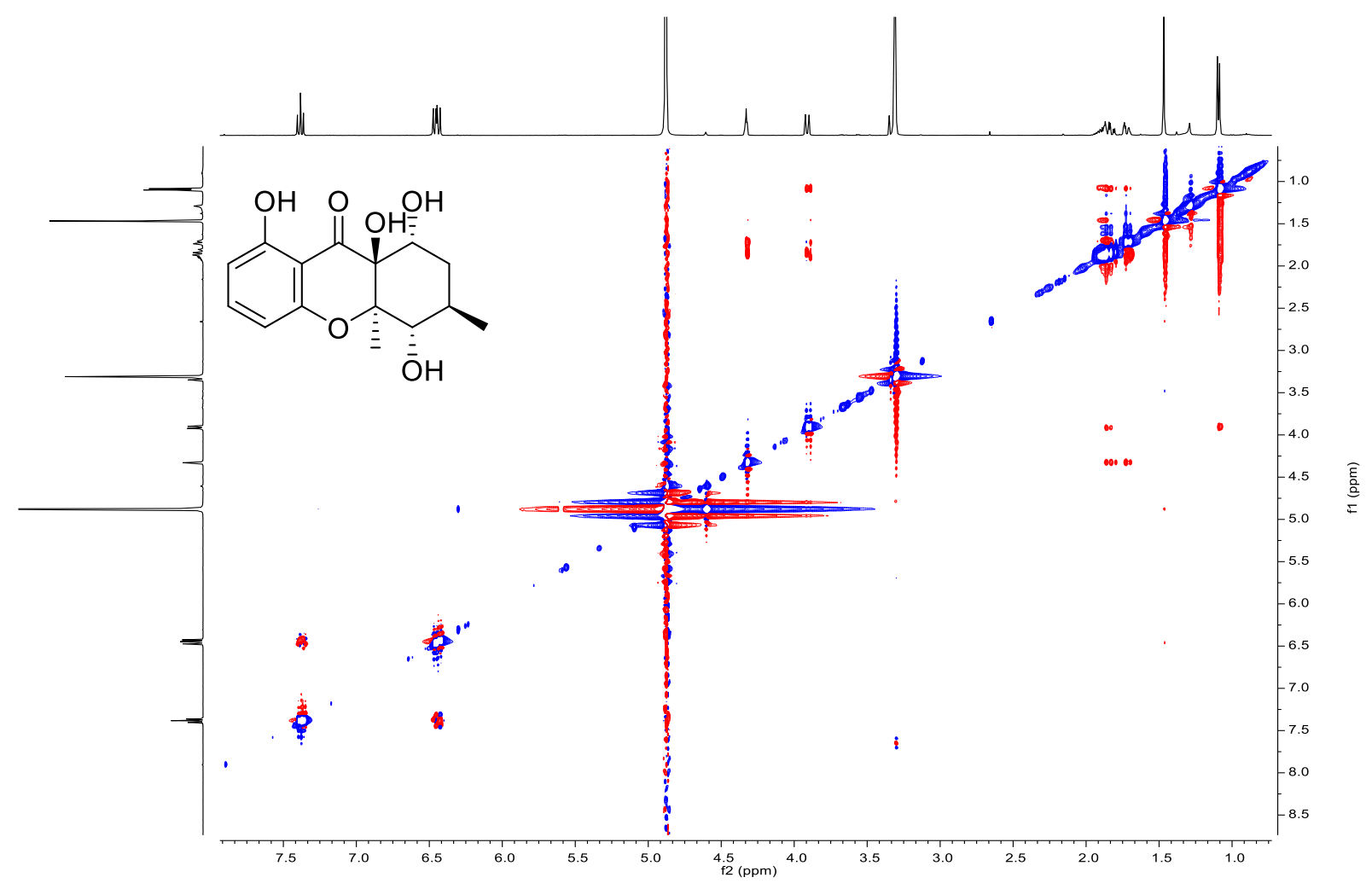

Figure S31. NOESY NMR of penicixanthone D (4) in $\mathrm{CD}_{3} \mathrm{OD}$. 


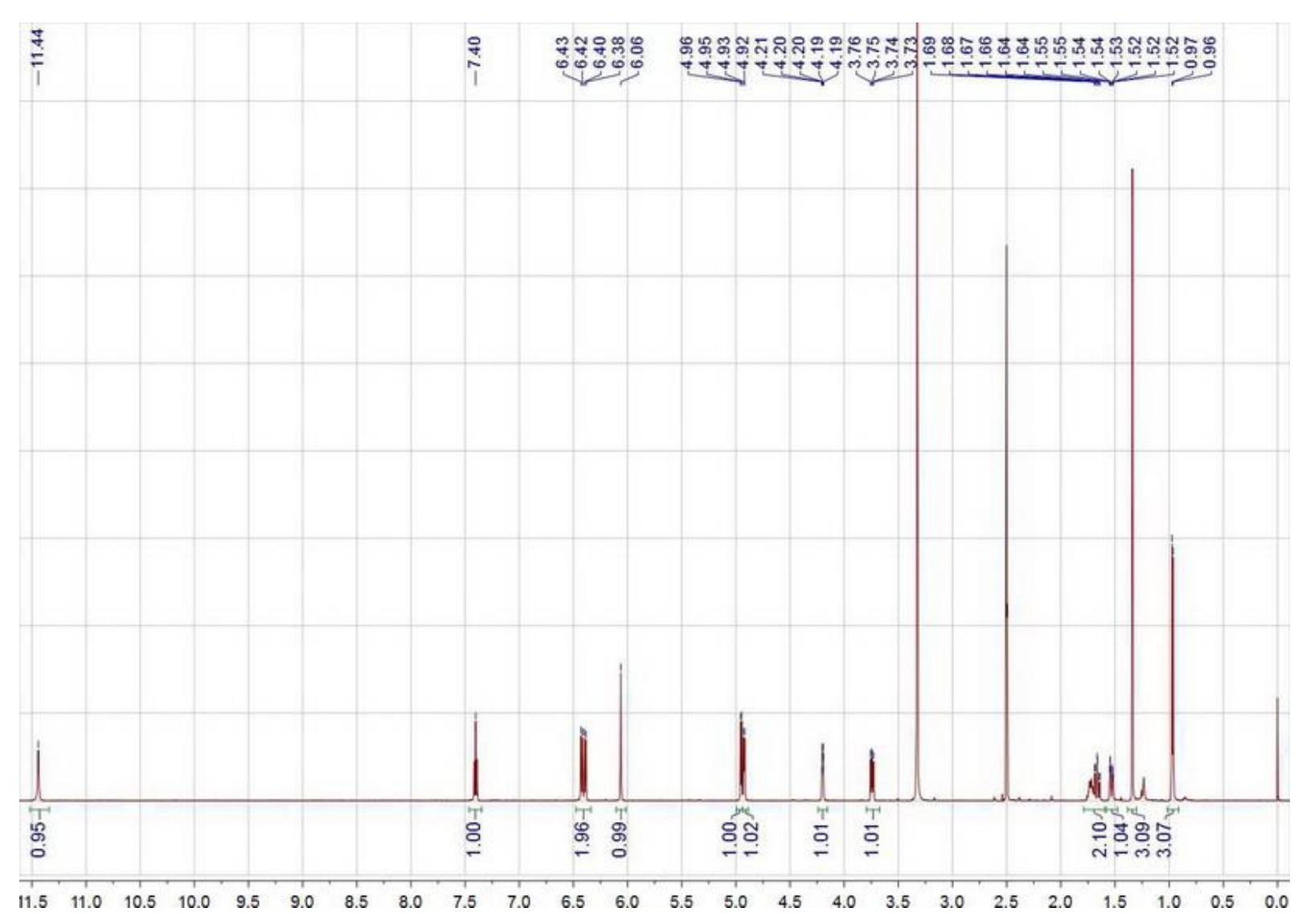

Figure S32. ${ }^{1} \mathrm{H}$ NMR spectrum of penicixanthone D (4) in DMSO- $d_{6}$.

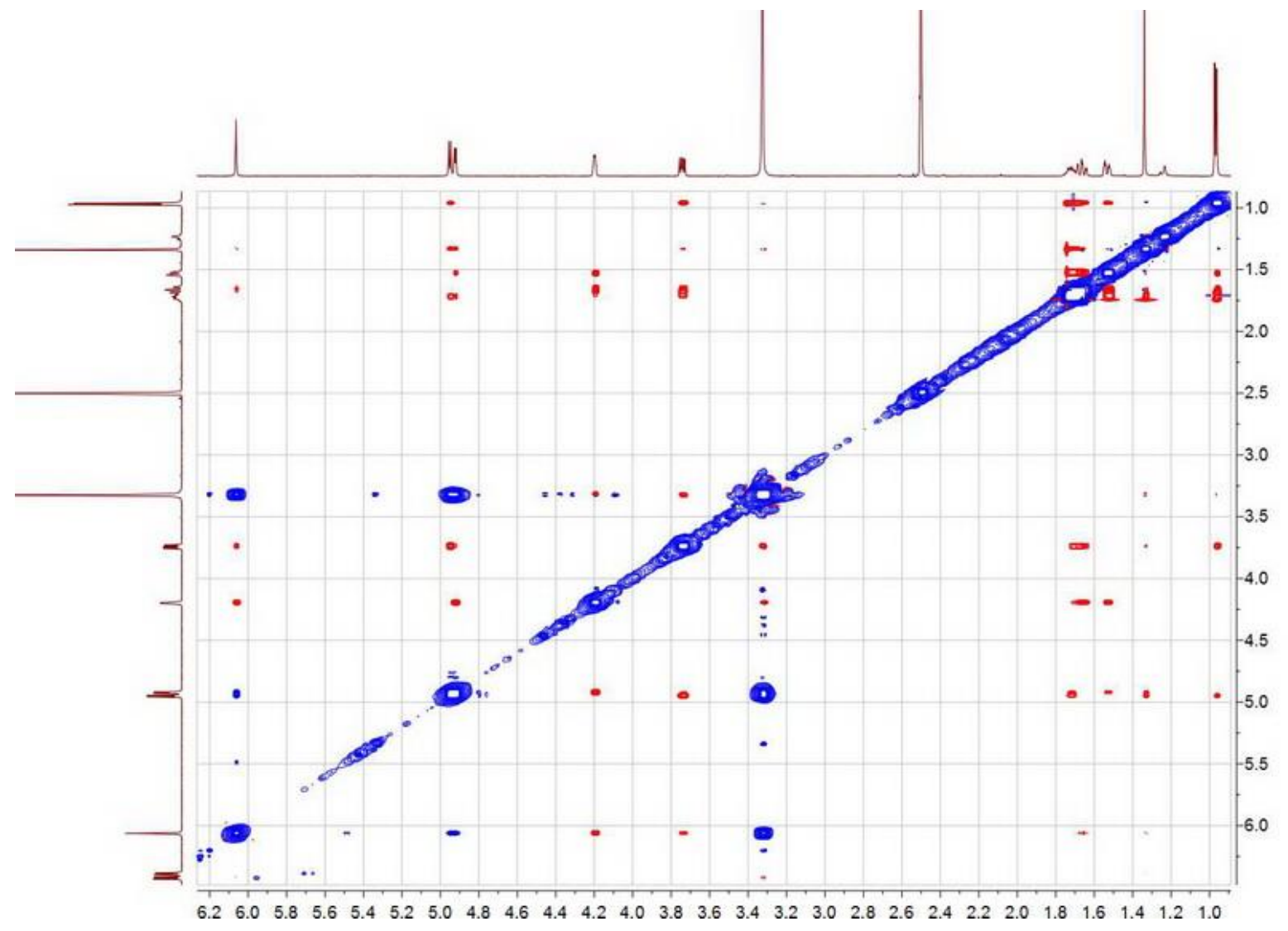

Figure S33. NOESY NMR of penicixanthone D (4) in DMSO- $d_{6}$. 


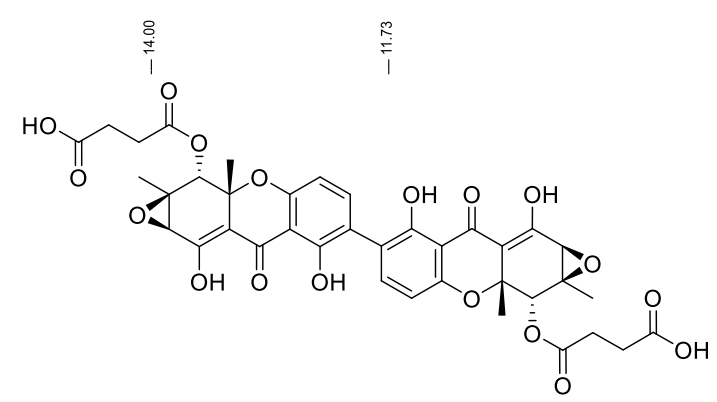

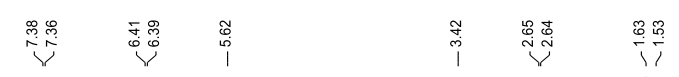

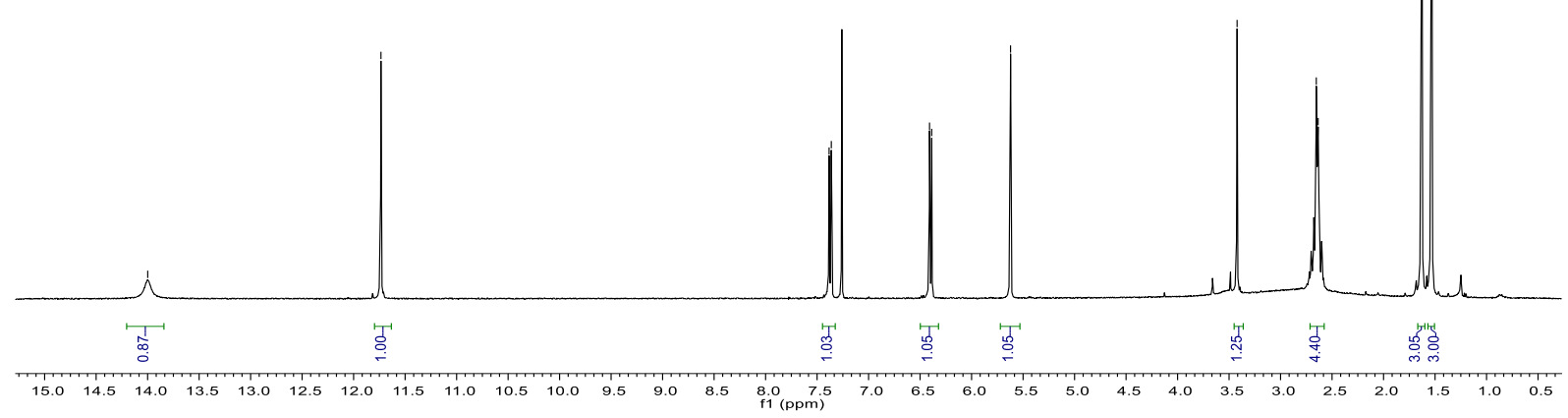

Figure S34. ${ }^{1} \mathrm{H}$ NMR spectrum of penicixanthone $\mathrm{E}(\mathbf{5})$ in $\mathrm{CDCl}_{3}$.
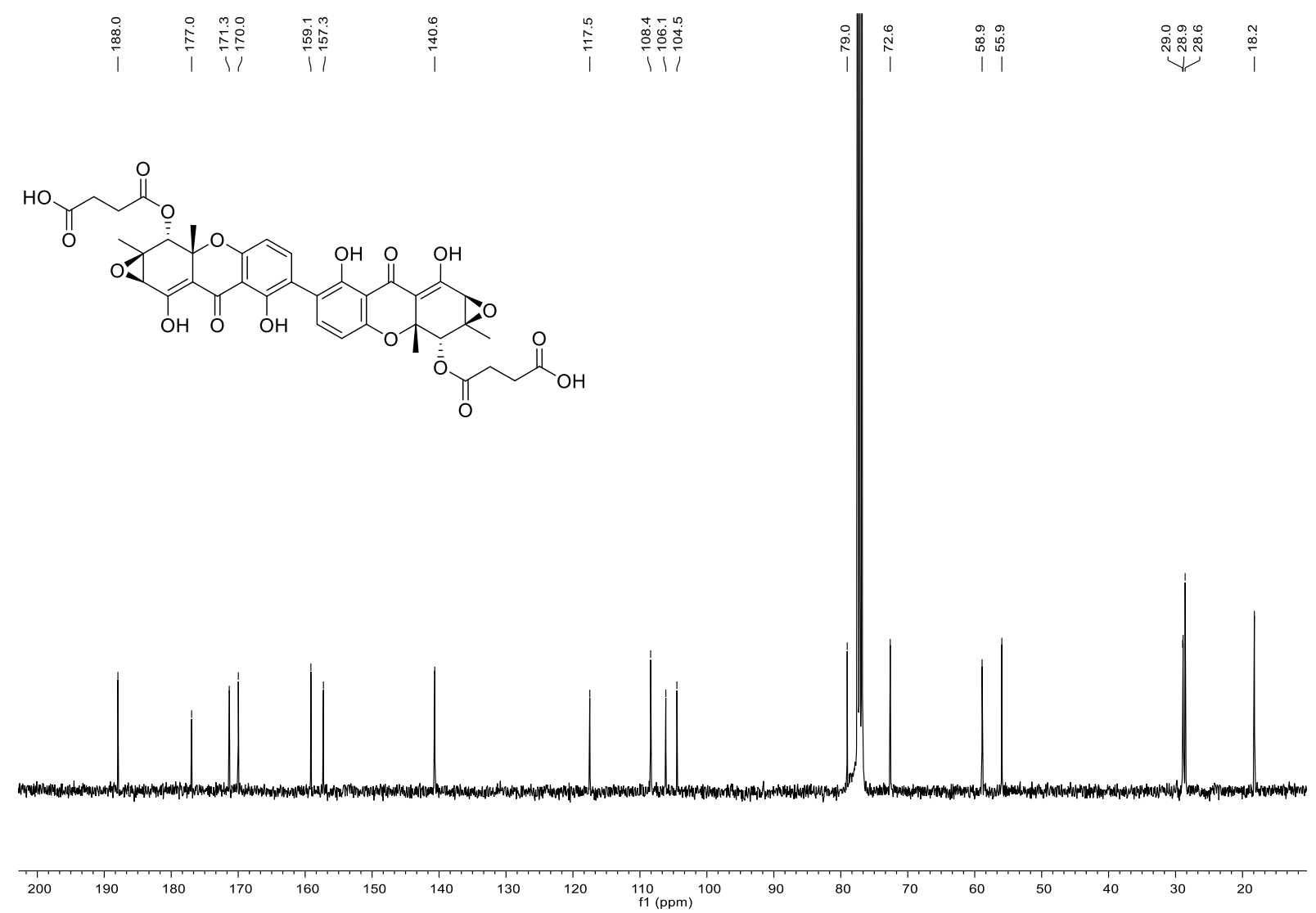

Figure S35. ${ }^{13} \mathrm{C}$ NMR spectrum of penicixanthone $\mathrm{E}(\mathbf{5})$ in $\mathrm{CDCl}_{3}$. 


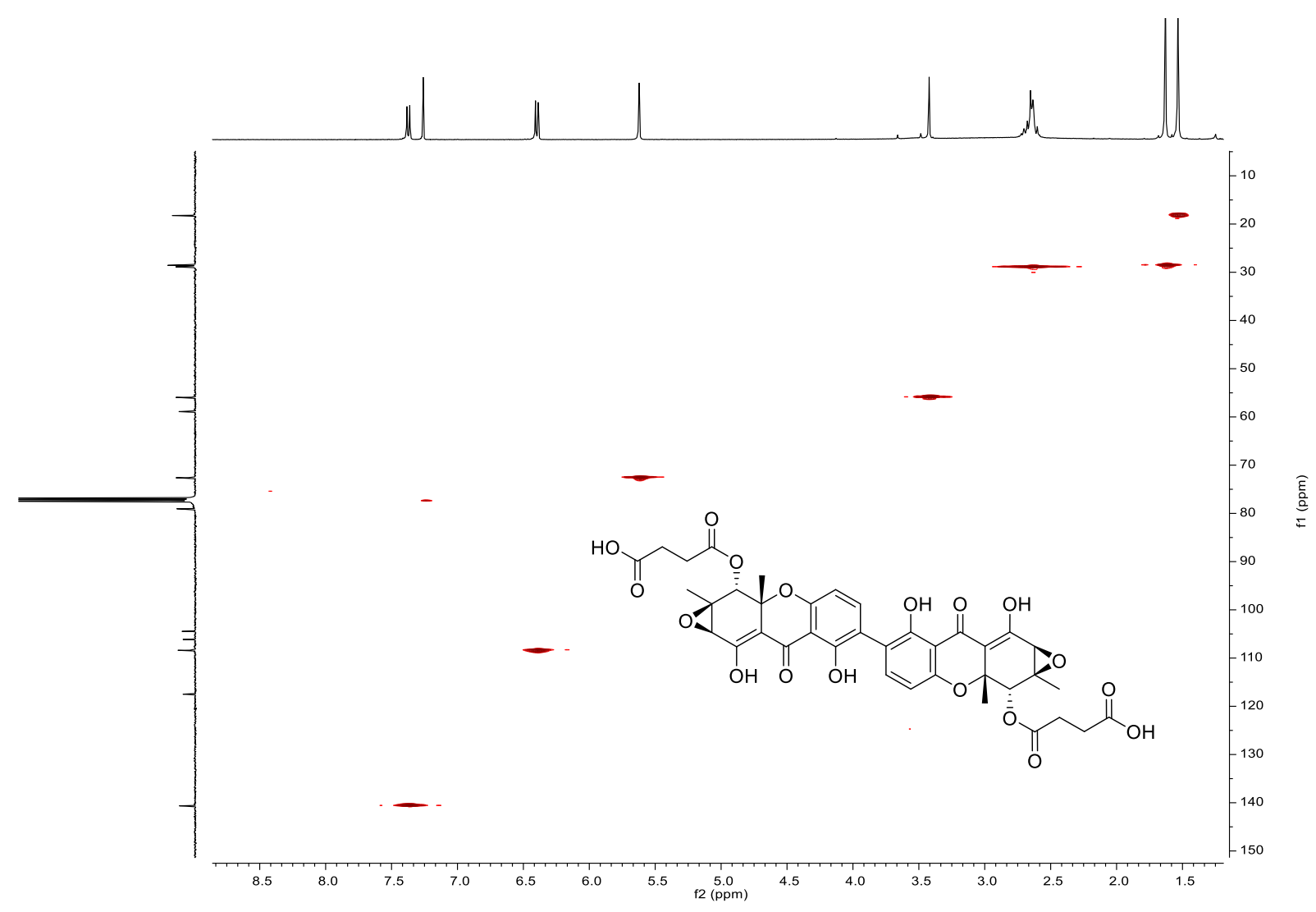

Figure S36. HSQC NMR of penicixanthone E (5) in $\mathrm{CDCl}_{3}$.

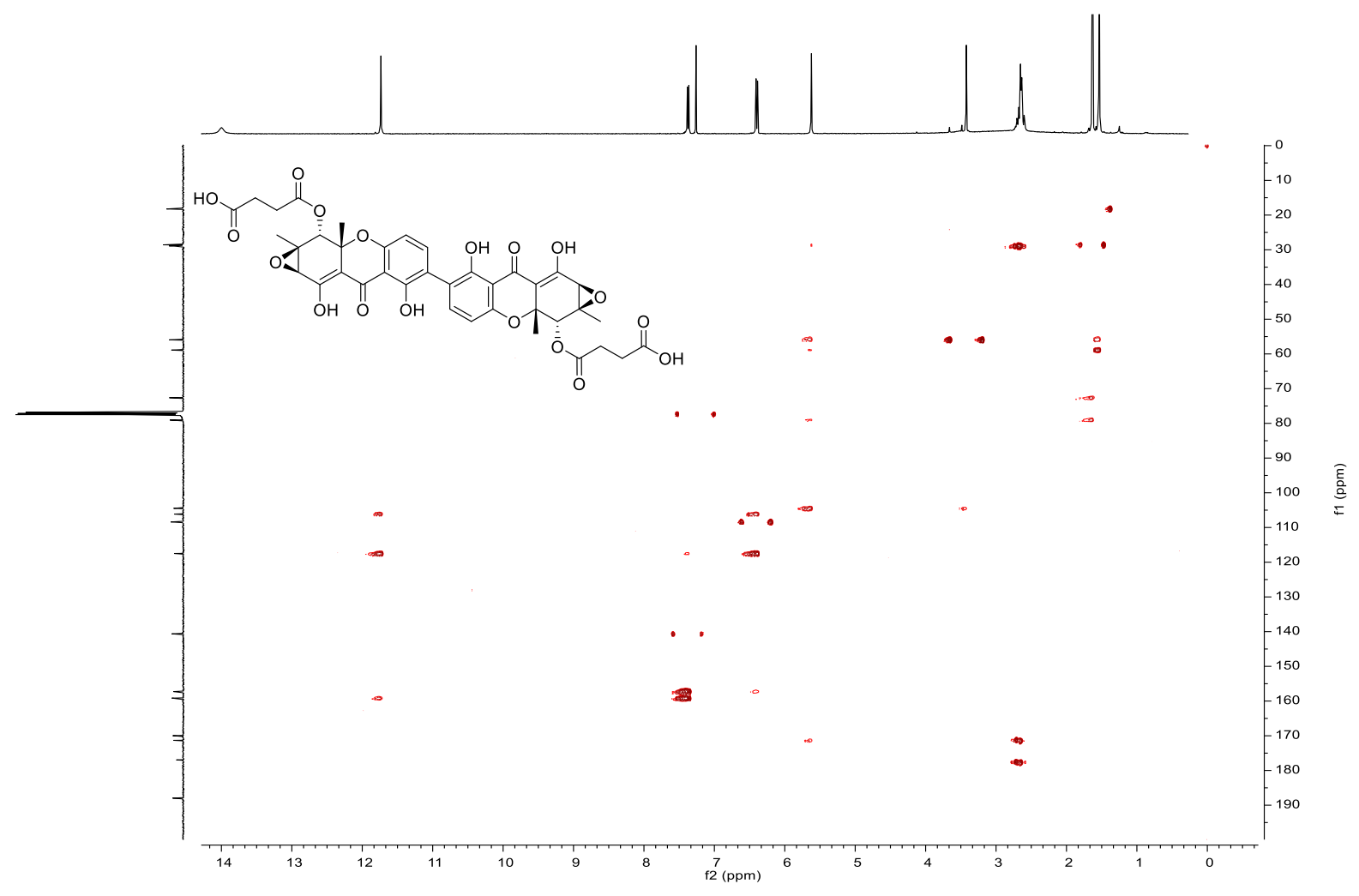

Figure S37. HMBC NMR of penicixanthone E (5) in $\mathrm{CDCl}_{3}$. 


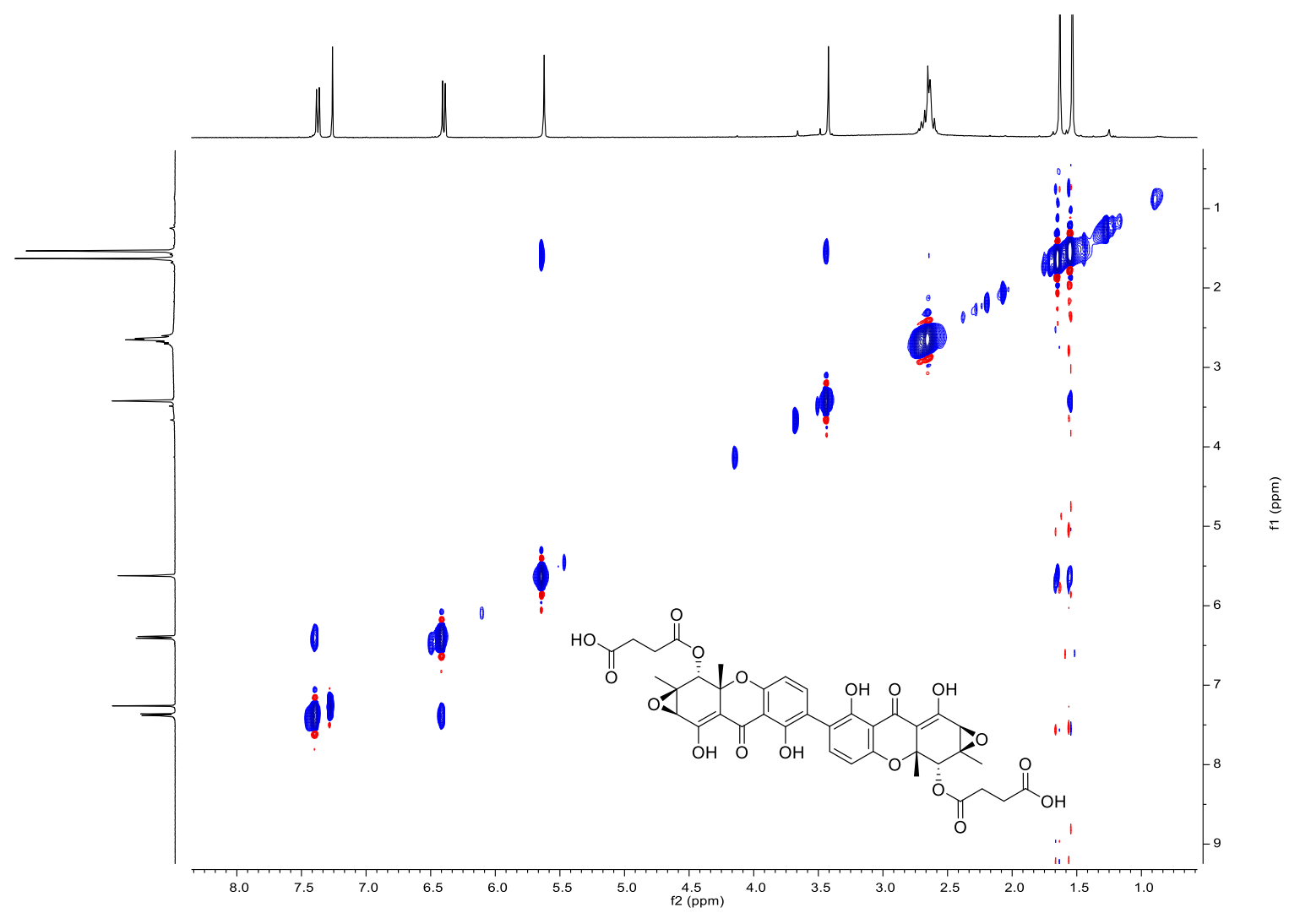

Figure S38. NOESY NMR of penicixanthone E (5) in $\mathrm{CDCl}_{3}$.
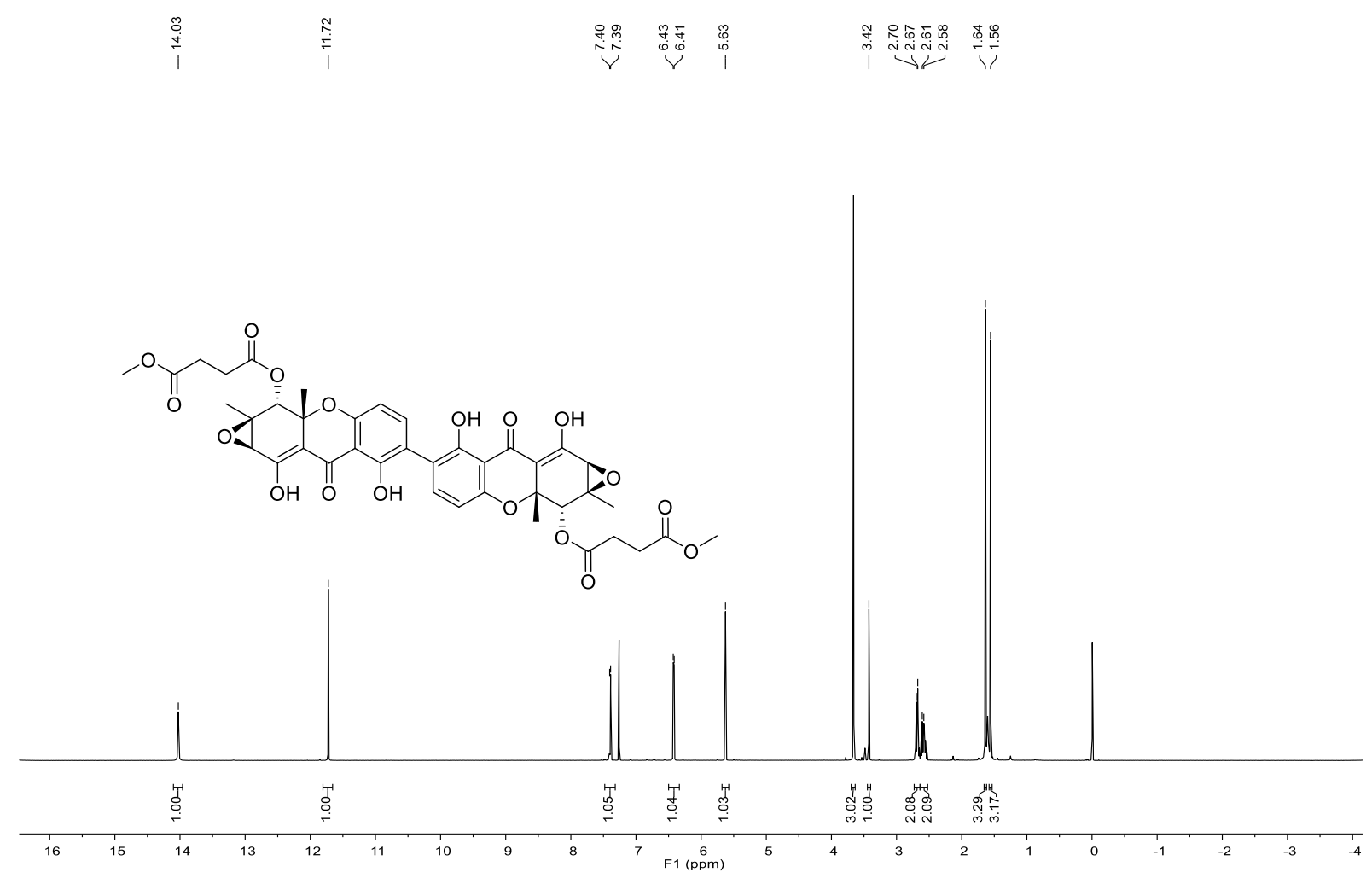

Figure S39. ${ }^{1} \mathrm{H}$ NMR spectrum of penicixanthone $\mathrm{F}(\mathbf{6})$ in $\mathrm{CDCl}_{3}$. 


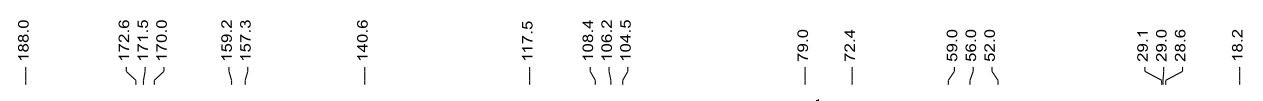
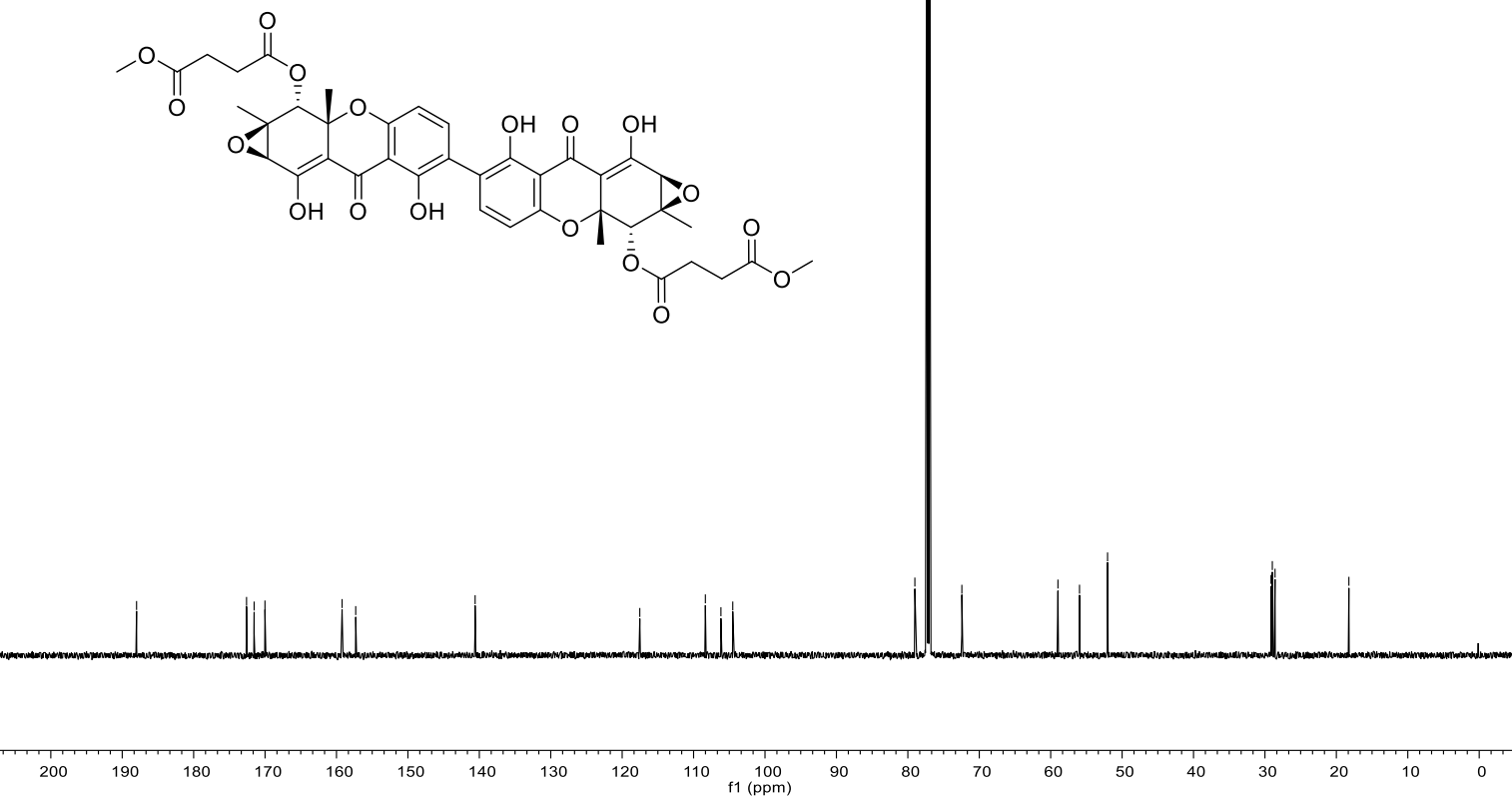

Figure S40. ${ }^{13} \mathrm{C}$ NMR spectrum of penicixanthone $\mathrm{F}(\mathbf{6})$ in $\mathrm{CDCl}_{3}$.

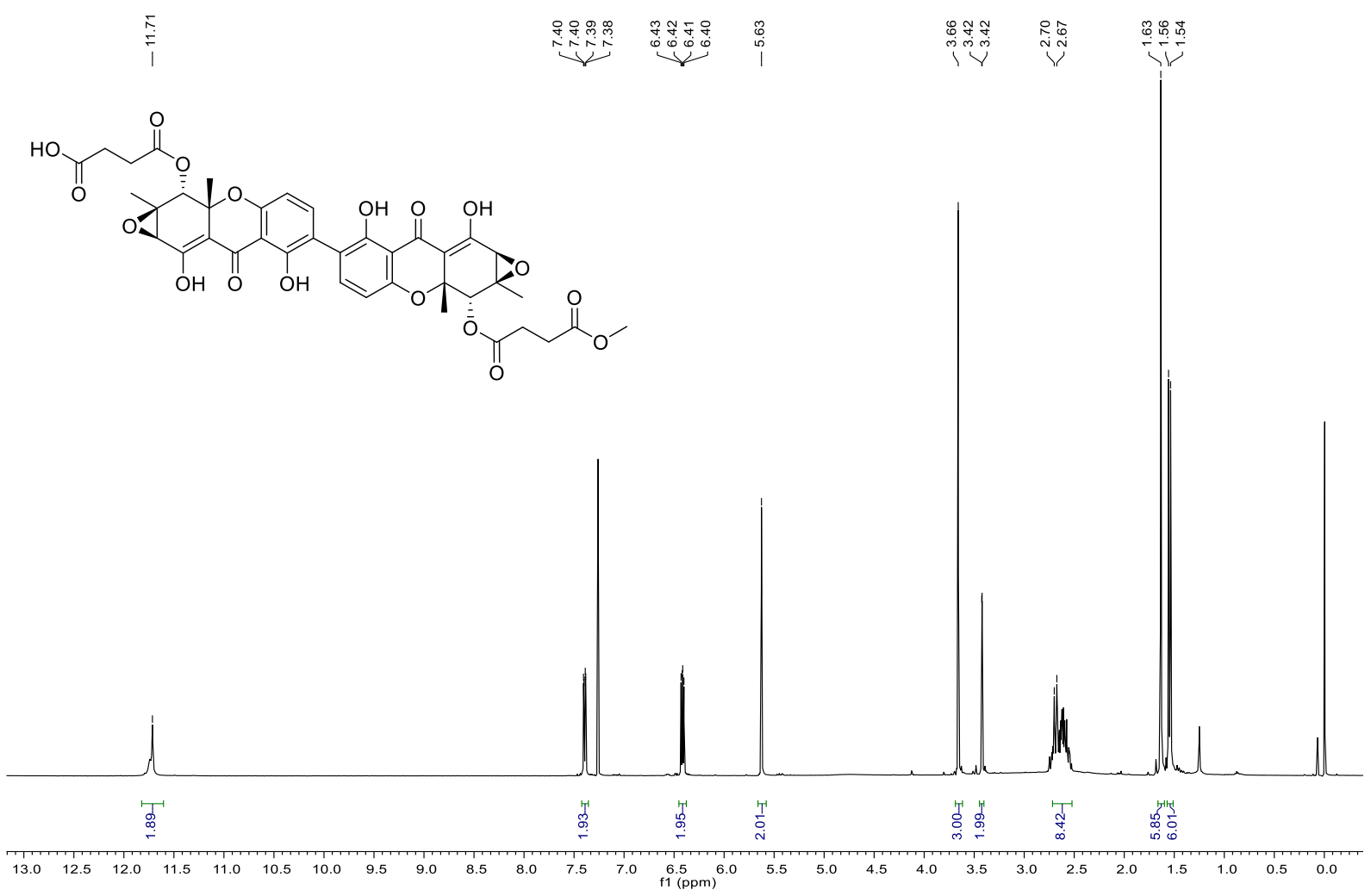

Figure S41. ${ }^{1} \mathrm{H}$ NMR spectrum of penicixanthone $\mathrm{G}(7)$ in $\mathrm{CDCl}_{3}$ 


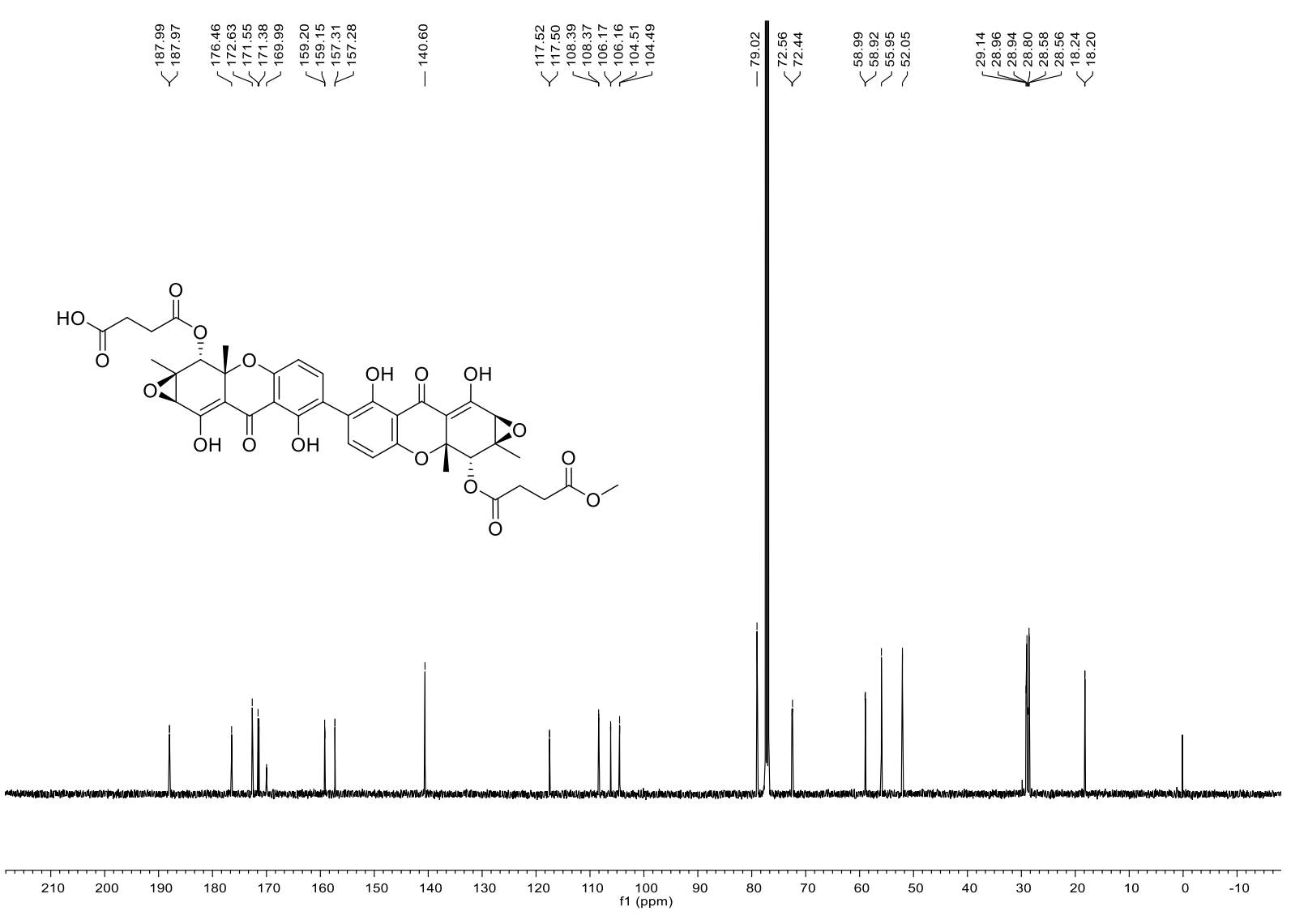

Figure S42. ${ }^{13} \mathrm{C}$ NMR spectrum of penicixanthone $\mathrm{G}(7)$ in $\mathrm{CDCl}_{3}$.

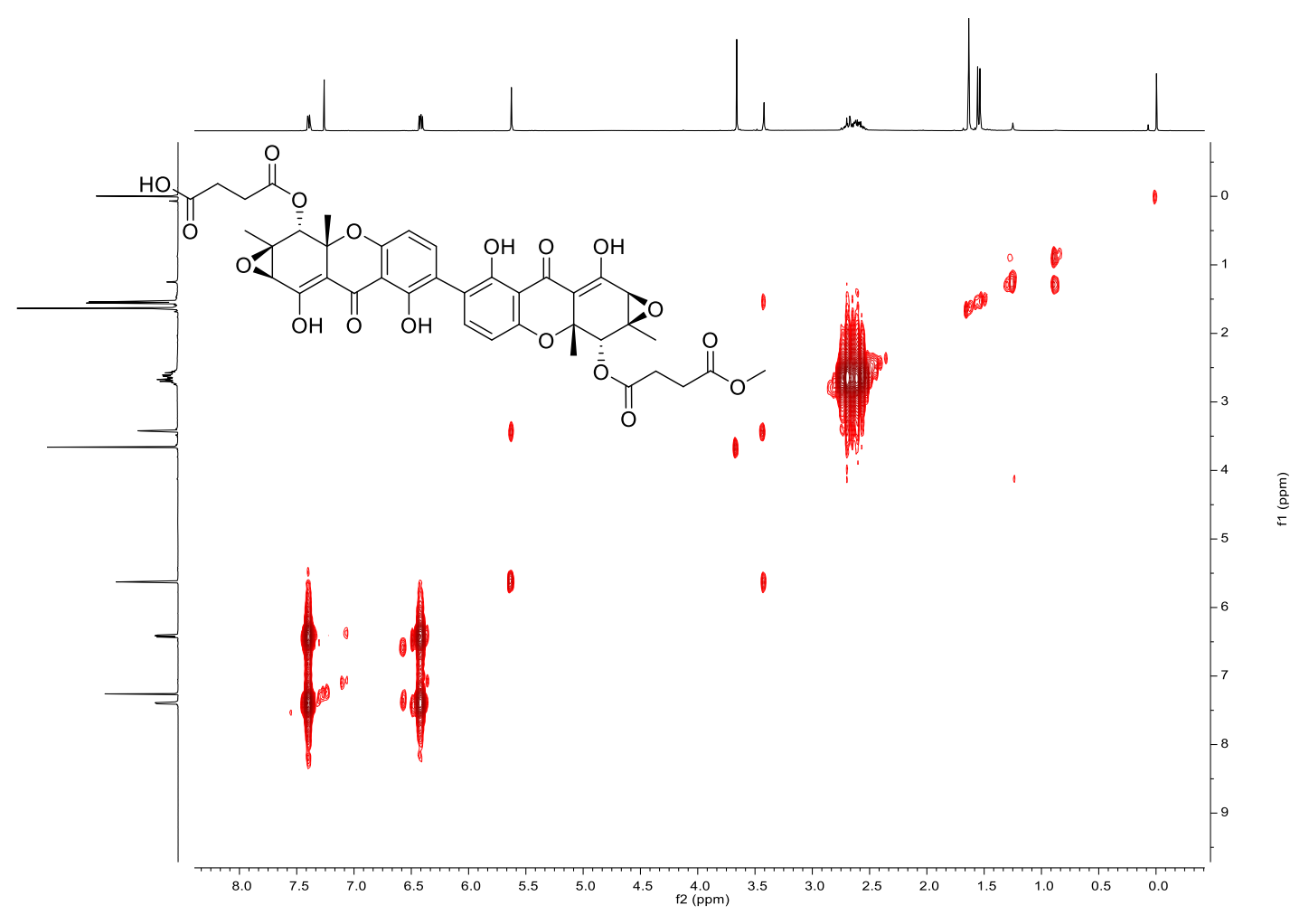

Figure S43. ${ }^{1} \mathrm{H}-{ }^{1} \mathrm{H}$ COSY NMR spectrum of penicixanthone $\mathrm{G}(7)$ in $\mathrm{CDCl}_{3}$. 


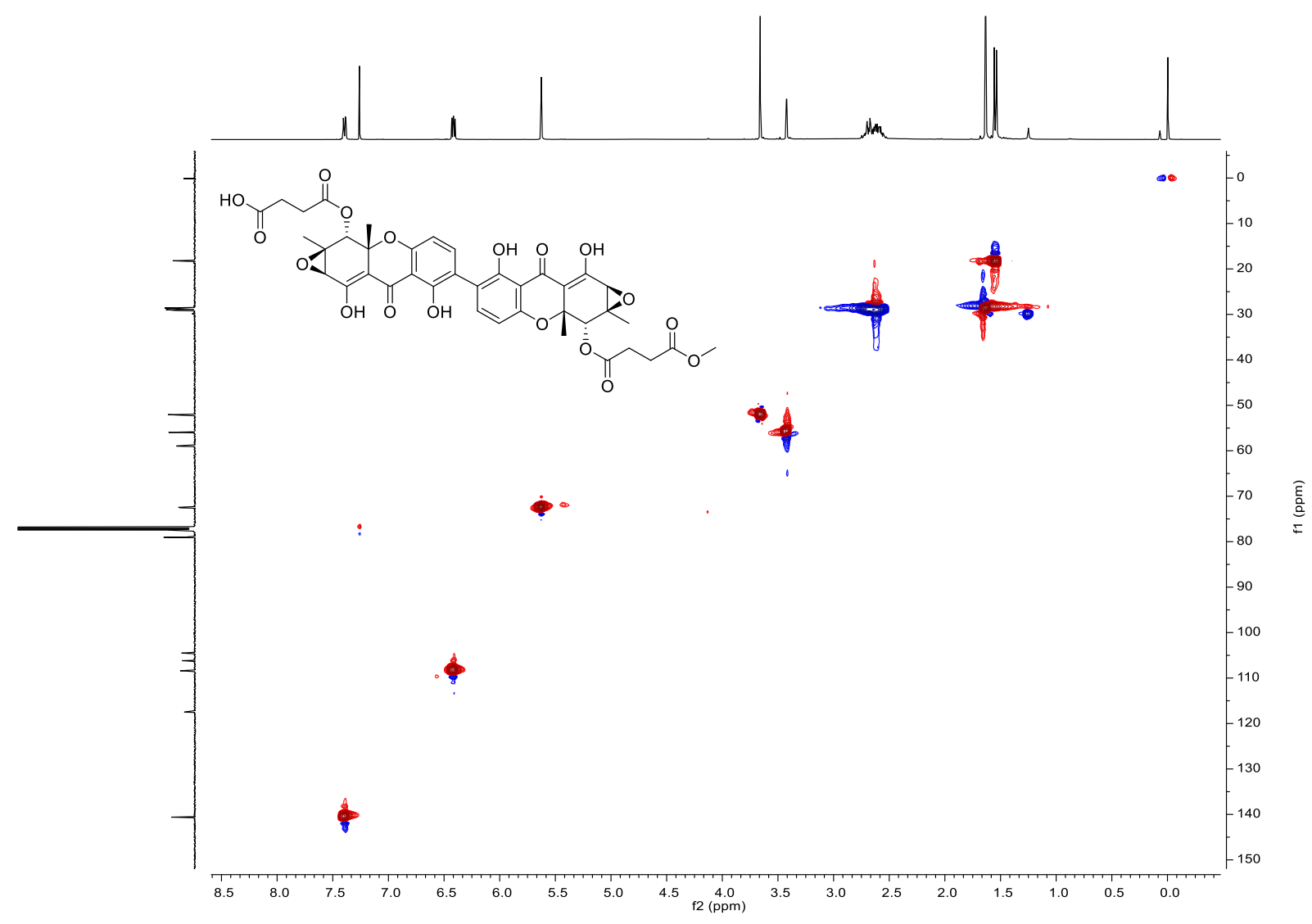

Figure S44. HSQC NMR of penicixanthone $\mathrm{G}(7)$ in $\mathrm{CDCl}_{3}$.

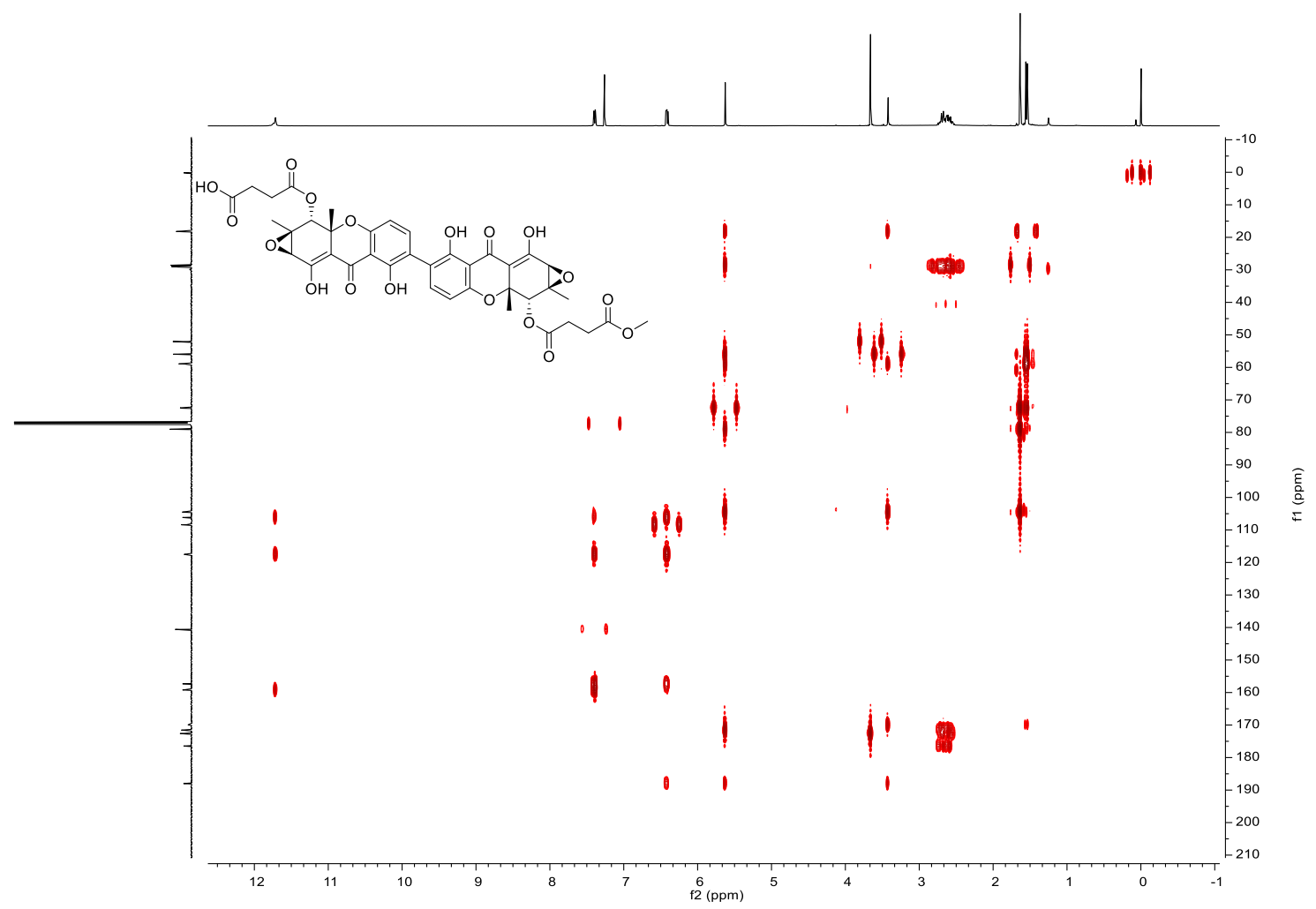

Figure S45. HMBC NMR of penicixanthone $\mathrm{G}(7)$ in $\mathrm{CDCl}_{3}$. 


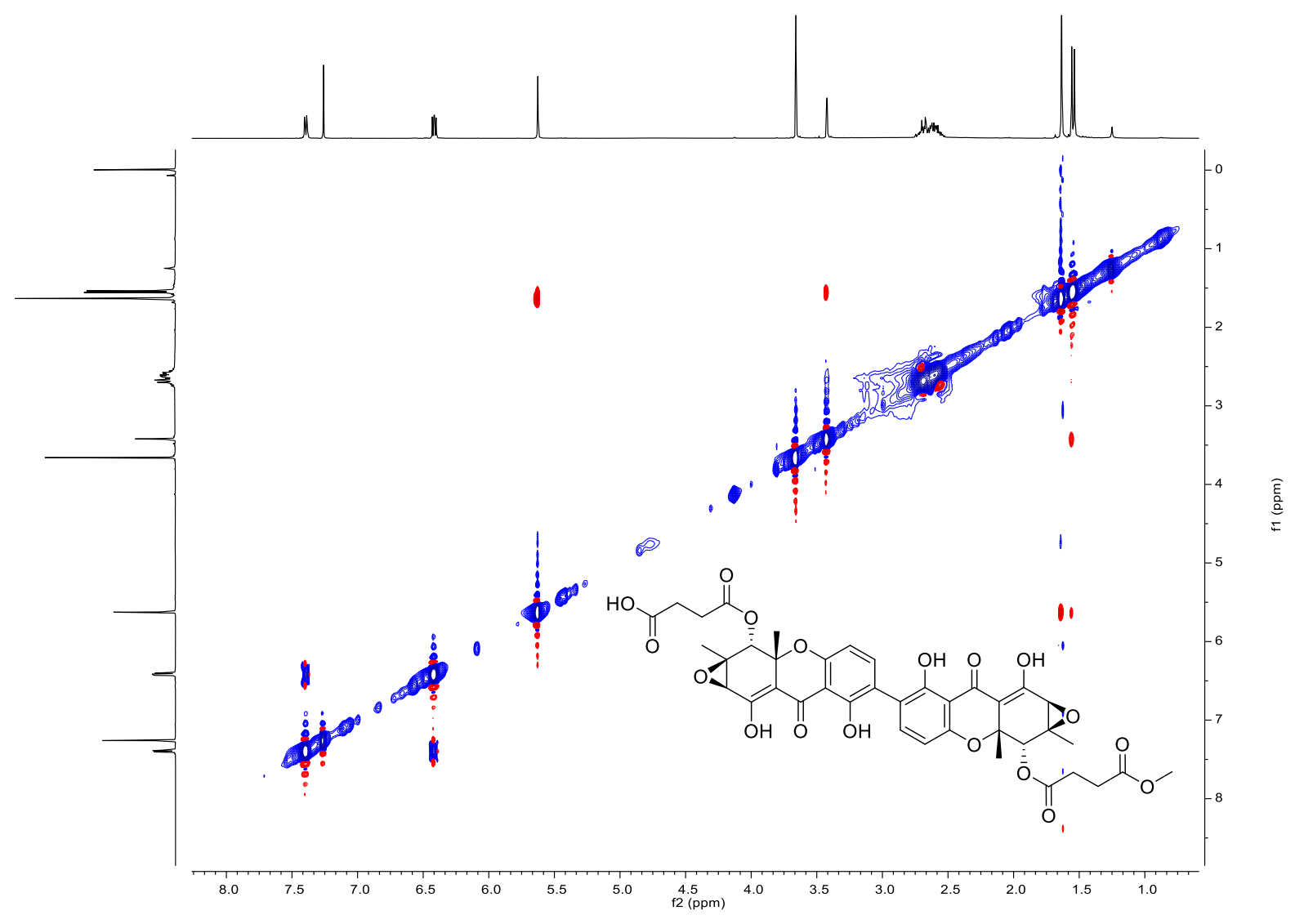

Figure S46. NOESY NMR of penicixanthone $\mathrm{G}(7)$ in $\mathrm{CDCl}_{3}$.

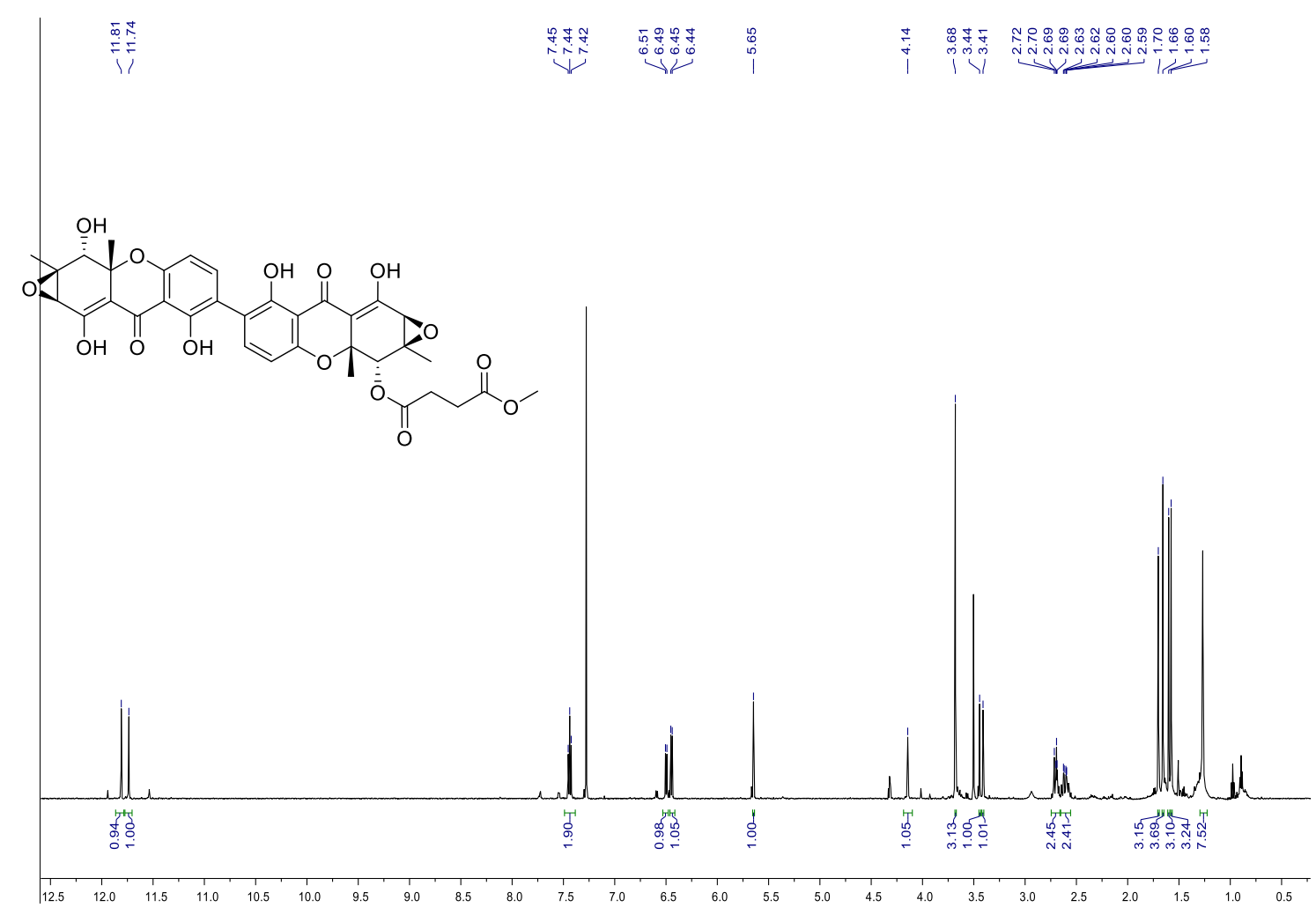

Figure S47. ${ }^{1} \mathrm{H}$ NMR spectrum of penicixanthone $\mathrm{H}(\mathbf{8})$ in $\mathrm{CDCl}_{3}$. 


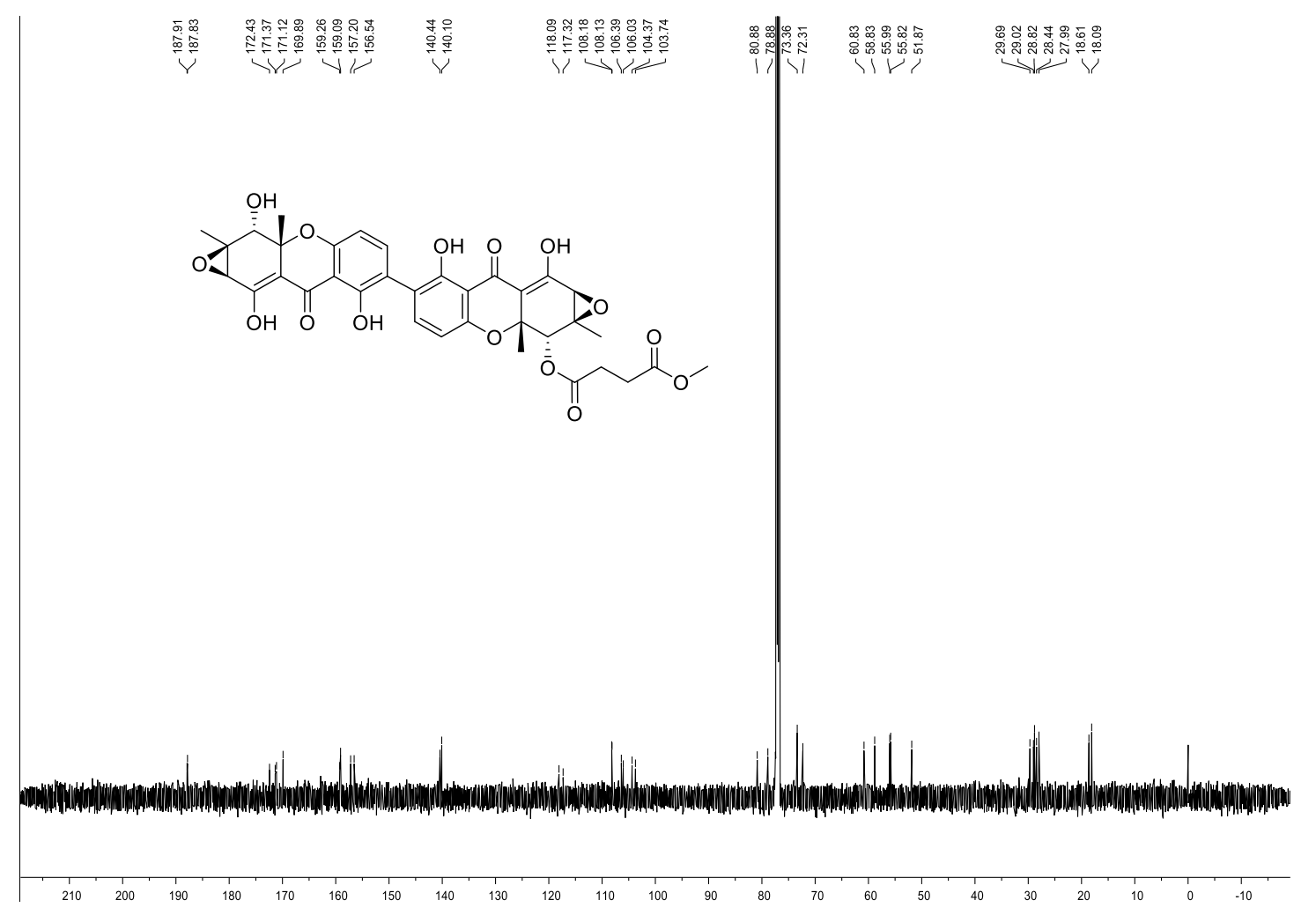

Figure S48. ${ }^{13} \mathrm{C}$ NMR spectrum of penicixanthone $\mathrm{H}(\mathbf{8})$ in $\mathrm{CDCl}_{3}$.

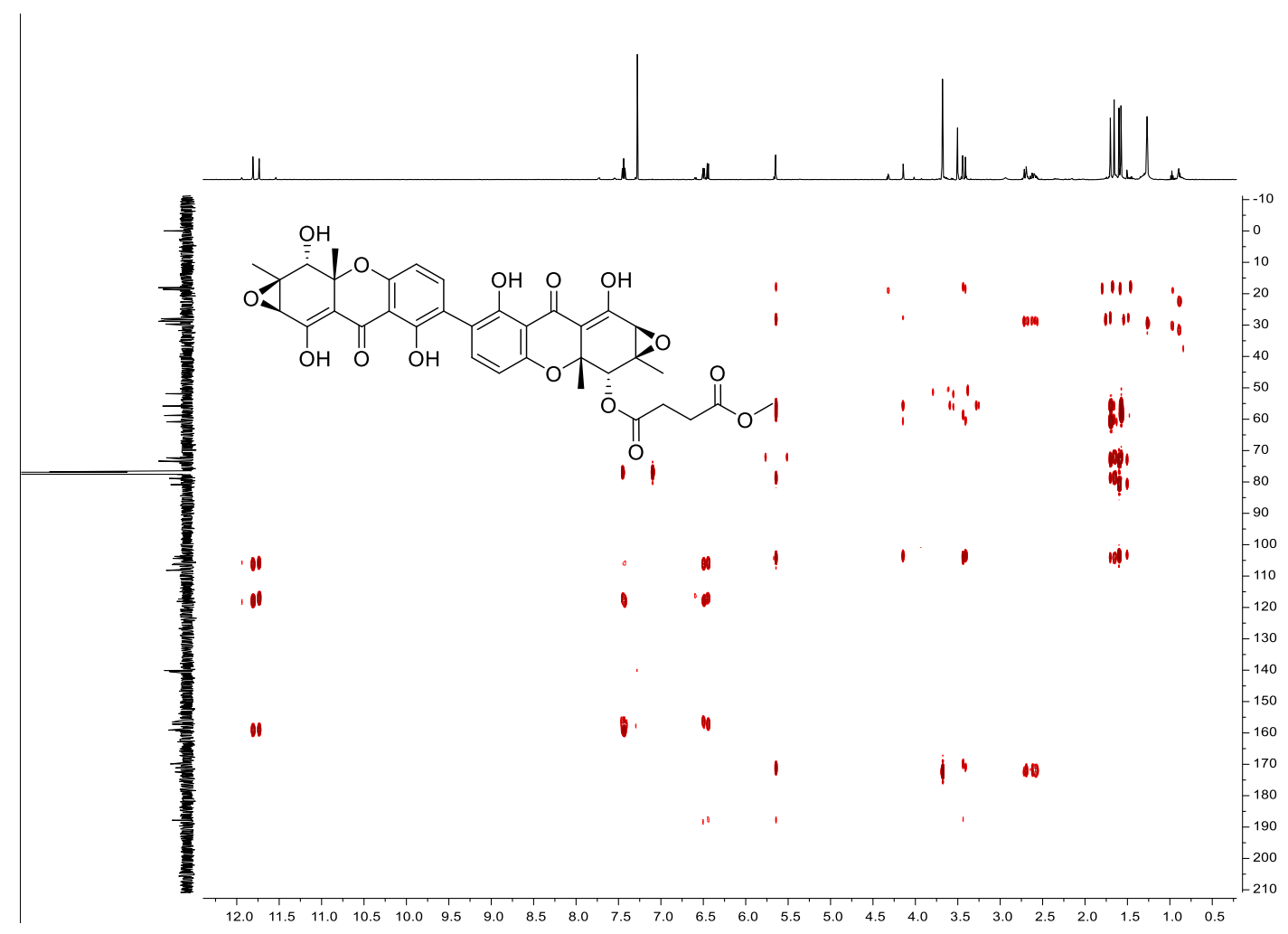

Figure S49. $\mathrm{HMBC}$ spectrum of penicixanthone $\mathrm{H}(\mathbf{8})$ in $\mathrm{CDCl}_{3}$. 